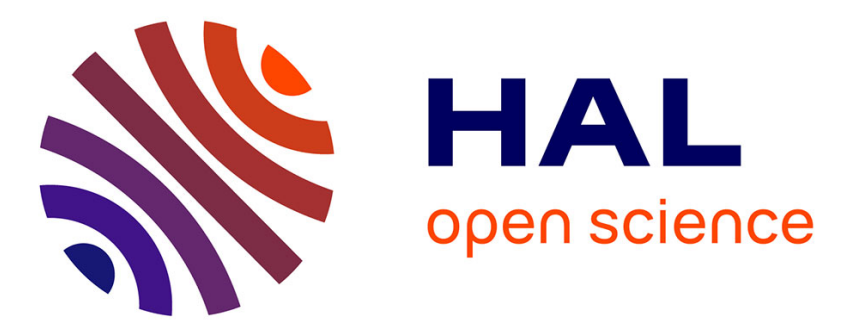

\title{
Precursor-Directed Assembly of Complex Oxide Nanobeads: The Role of Strongly Coordinated Inorganic Anions
}

O. Nikonova, Jean-Marie Nedelec, V.G. Kessler, G. Seisenbaeva

\section{- To cite this version:}

O. Nikonova, Jean-Marie Nedelec, V.G. Kessler, G. Seisenbaeva. Precursor-Directed Assembly of Complex Oxide Nanobeads: The Role of Strongly Coordinated Inorganic Anions. Langmuir, 2011, 27 (18), pp.11622. 10.1021/la2028719 . hal-00673070

\section{HAL Id: hal-00673070 \\ https://hal.science/hal-00673070}

Submitted on 22 Feb 2012

HAL is a multi-disciplinary open access archive for the deposit and dissemination of scientific research documents, whether they are published or not. The documents may come from teaching and research institutions in France or abroad, or from public or private research centers.
L'archive ouverte pluridisciplinaire HAL, est destinée au dépôt et à la diffusion de documents scientifiques de niveau recherche, publiés ou non, émanant des établissements d'enseignement et de recherche français ou étrangers, des laboratoires publics ou privés. 


\section{Precursor-directed assembly of complex oxide nanobeads.} The role of strongly coordinated inorganic anions

\begin{tabular}{|r|l|}
\hline Journal: & Langmuir \\
\hline Manuscript ID: & la-2011-028719 \\
\hline Manuscript Type: & Article \\
\hline Author: & $25-J u l-2011$ \\
\hline Complete List of Authors: & $\begin{array}{l}\text { Nikonova, Olesya; SLU, Chemistry } \\
\text { Nedelec, Jean-Marie; Clermont université, Chemistry } \\
\text { Kessler, Vadim; SLU, Department of Chemistry } \\
\text { Seisenbaeva, Gulaim; SLU, Chemistry }\end{array}$ \\
\hline
\end{tabular}

\section{SCHOLARONE Manuscripts}


Precursor-directed assembly of complex oxide nanobeads. The role of strongly coordinated inorganic anions
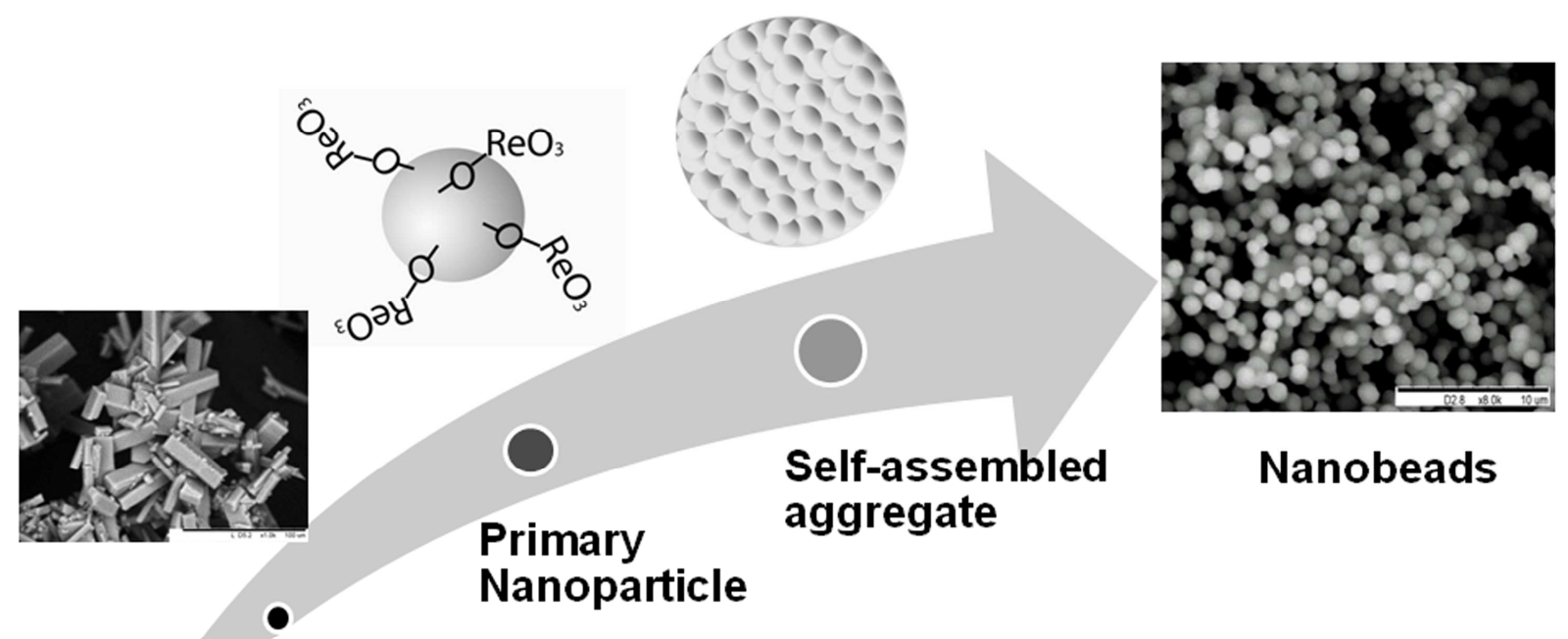

Nanobeads

\section{Alkoxide \\ Precursor}




\title{
Precursor-directed assembly of complex oxide nanobeads. The role of strongly coordinated inorganic anions
}

\author{
Olesya A. Nikonova, ${ }^{\dagger}$ Jean-Marie Nedelec, ${ }^{\ddagger}$ Vadim G. Kessler, ${ }^{\dagger, *}$ and Gulaim A. \\ Seisenbaeva, ${ }^{\dagger, *}$
}

$\dagger$ Department of Chemistry, BioCenter SLU, Box 7015, 75007 Uppsala, Sweden, Vadim.Kessler@slu.se, † Clermont Université, ENSCCF, Laboratoire des Matériaux Inorganiques, BP 10448, F-63000 Clermont-Ferrand, France, CNRS, UMR 6002, LMI, F-63177 Aubière, France,

\begin{abstract}
Use of an inorganic perrhenate ligand in the structure of early transition metal alkoxide precursors permits to achieve uniform self-assembly of the primary nanoparticles produced by their hydrolysis. The latter has been carried out in hydrocarbon reaction medium by addition of water on vigorous stirring, either in the pure form or in solutions in parent alcohols. The selfassembly is guided by the surface charge enhanced by the presence of strongly coordinated anions as determined by zeta-potential measurements. The aggregation process has been followed in real time by Nanoparticle Tracking Analysis (NanoSight technique). The reaction products are spherical aggregates with the size that can be efficiently controlled through polarity of the reaction medium. The produced nanobeads have been characterized by TEM, SEM-EDS, DLS, nitrogen adsorption and FTIR. The coordination of metal centers has been investigated using EXAFS-spectroscopy. The aggregates remain amorphous on thermal treatment up to $700^{\circ} \mathrm{C}\left(24 \mathrm{~h}\right.$ treatment), but crystallize, when treated at $1000^{\circ} \mathrm{C}$. This latter process is associated with the total loss of rhenium content and offers early transition metal oxides as products.
\end{abstract}




\section{Introduction}

Formation of 3D-aggregates of self-assembled nanoparticles has recently attracted much attention $^{1,2,3,4,5}$ in the view of a broad spectrum of applications foreseen for these constructions, ranging from optical ${ }^{1,2}$ and magnetic ${ }^{3}$ lenses to high-stability electrode materials for lithium-ion batteries $^{4}$ and dye-sensitized solar cells ${ }^{5}$. Among the approaches proposed to control the selfassembly major focus has been on either application of surfactants ${ }^{3}$, , including graftcopolymers ${ }^{6}$. Even in the absence of surfactants, the action of weak inter-particle forces, such as Van-der-Waals or electrostatic interactions have been proposed to explain uniform self-assembly in solution ${ }^{7}$, observed generally for metal oxide nanoparticles ${ }^{4,8,9,10}$. The aggregation of metal oxide nanoparticles has been proved to be facilitated even by hydro- or solvothermal synthesis ${ }^{4,11}$.

A special attention has been recently directed towards oxide nanobeads involving one or several early transition elements as perspective materials for Li-battery electrodes and for oxidation or acidic catalysis ${ }^{12,13}$.The applied structure-directing tools have in this case been either application of sol-gel technology in complex solvent mixtures ${ }^{12}$ or using external templates ${ }^{13}$. Formation of spherical particles on spontaneous hydrolysis of alkoxide precursors on liquid-air interface in contact with moist air has been reported long ago, but no means for control of particle size and aggregation have been developed yet ${ }^{14}$. The advantage of use of metal alkoxides as precursors lies in the formation via their hydrolysis of uniform oxometallate primary nanoparticles with the size below $5 \mathrm{~nm}$ - products of coordination equilibrium. ${ }^{10,15}$ A lot of effort has been put recently on the investigation of the role of different factors to control formation and aggregation of nanoparticles in aqueous media, envisaging, in particular, the role of coordinated anions. ${ }^{16}$ In the present work we have successfully exploited introduction of an inorganic perrhenate anion in the structure of metal-organic precursors to achieve the uniform self-assembly of the initial particles. The size of the produced spherical aggregates could be efficiently controlled through the polarity of the medium (introduction of alcohols into hydrocarbon reaction medium). 


\section{Experimental}

All the preparative procedures were carried out in dry nitrogen atmosphere using a dry box. Toluene was dehydrated by refluxing over $\mathrm{LiAlH}_{4}$ with subsequent distillation. Methanol was purified by distillation over magnesium methoxide. Ethanol was dried by refluxing over Ba ethoxide, and n-propanol - by refluxing over aluminium n-propoxide with subsequent distillation.

The alkoxides, used in this work as starting materials for the synthesis of bi- and trimetallic complexes, $\mathrm{Nb}_{2}(\mathrm{OMe})_{10}$ and $\mathrm{Ta}_{2}(\mathrm{OMe})_{10}$, were prepared by anodic oxidation of the corresponding metals in methanol and purified according to conventional techniques ${ }^{19}$. The $\mathrm{Ta}\left(\mathrm{OCH}_{2} \mathrm{CH}_{3}\right)_{5} 99+\%(\mathrm{~L} 10288)$ and $\mathrm{Nb}\left(\mathrm{OC}_{3} \mathrm{H}_{7}\right)_{5} 99 \%$ (36571) have been purchased from Alfa Aesar. Preparation of the precursor complexes $\left(\mathbf{N b}_{\mathbf{x}} \mathbf{T a} \mathbf{a}_{1-\mathbf{x}}\right)_{\mathbf{4}} \mathbf{O}_{\mathbf{2}}(\mathbf{O E t})_{\mathbf{1 4}}\left(\mathbf{R e O} \mathbf{O}_{4}\right)_{\mathbf{2}}(\mathbf{I})$, $\left(\mathbf{N b}_{\mathbf{x}} \mathbf{T a}_{1-}\right.$ $\left.{ }_{x}\right)_{4} \mathrm{O}_{2}(\mathrm{OMe})_{14}\left(\mathrm{ReO}_{4}\right)_{2} \quad$ (II), $\mathrm{Nb}_{4} \mathrm{O}_{2}\left(\mathrm{O}^{\mathrm{n}} \mathrm{Pr}\right)_{14}\left(\mathrm{ReO}_{4}\right)_{2} \quad$ (III) $\mathrm{Nb}_{4} \mathrm{O}_{2}(\mathrm{OEt})_{14}\left(\mathrm{ReO}_{4}\right)_{2} \quad$ (IV), $\mathrm{Nb}_{4} \mathrm{O}_{2}(\mathrm{OMe})_{14}\left(\mathrm{ReO}_{4}\right)_{2}(\mathrm{~V}), \mathrm{Ta}_{4} \mathrm{O}_{2}(\mathrm{OEt})_{14}\left(\mathrm{ReO}_{4}\right)_{2}(\mathrm{VI})$ and $\mathrm{Ta}_{4} \mathrm{O}_{2}(\mathrm{OMe})_{14}\left(\mathrm{ReO}_{4}\right)_{2}$ (VII), followed procedures described earlier for compounds II and IV in ${ }^{20,21}$ and are described in detail in the Supplementary.

IR spectra of tablets pressed with dry $\mathrm{KBr}$ were obtained with a Perkin Elmer FT-IR spectrometer Spectrum-100. Mass-spectra were recorded using JEOL JMS-SX/SX-102A massspectrometer applying electron beam ionization $(\mathrm{U}=70 \mathrm{eV})$ with direct probe introduction. ${ }^{1} \mathrm{H}$ NMR spectra were collected for the precursors on Bruker DRX 400 spectrometer. The details of spectroscopic and crystallographic characterization of precursor compounds can be obtained from the Supplementary (Tables TS1-TS3).

SEM micrographs of the samples were obtained in scanning electron microscope HITACHI TM$1000 \mu$ Dex, equipped with EDAX analysis. The RSD for all elements have been determined by repeating the EDS analysis 10 times from the same area on the highest magnification. TEM images were obtained with Philips TEM/STEM 400 instrument. Specific surface areas (SSA) were measured at $77 \mathrm{~K}$ on a Quantachrome Autosorb 1 apparatus. SSA was determined from at 
least 5 points in the $0.05-0.3 \mathrm{P} / \mathrm{P}_{0}$ range. Hydrodynamic size and $\zeta$ potential were measured using the dynamic light scattering (DLS) technique on Malvern Instruments Zetasizer Nano-ZS instrument operating under a He_Ne $633 \mathrm{~nm}$ laser and equipped with the Dispersion Technology Software for data collection and analysis. The samples were sonicated in $15 \mathrm{~min}$ before each measurement. All measurements have been carried out in duplicate and revealed high reproducibility.

EXAFS - Data collection. Tantalum and Rhenium K edge X-ray absorption spectra were recorded at the wiggler beam line I811 at the MAXLab, Lund University, Lund; Sweden. The EXAFS station was equipped with a Si [111] double crystal monochromator. The data collection was performed in transmission mode. Higher order harmonics were reduced by detuning the second monochromator to $30 \%$ of maximum intensity at the end of the scans. The energy scale of the X-ray absorption spectra were calibrated by assigning the first inflection point of the $\mathrm{K}$ edge of a tantalum foil to $9881 \mathrm{eV}^{17}$. The EXAFSPAK program package ${ }^{18}$ was used for the data treatment.

\section{Preparation of nanobeads}

Two types of hydrolysis: natural and forced have been applied to obtain spherical aggregates denoted below as nanobeads. Certain masses of the precursor crystals were taken from the mother liquor and dissolved in different volumes of toluene, depending on the solubility of the alkoxides. Natural hydrolysis was carried out by slow diffusion of the ambient atmosphere into a flask with solution of alkoxide precursor connected with air through a syringe needle piercing the serum cup. The forced hydrolysis was carried out by addition of liquid water in two different protocols: (1) $0.01 \mathrm{ml}$ of $\mathrm{H}_{2} \mathrm{O}$ was quickly added by syringe on shaking to $0.5 \mathrm{ml}$ of toluene solution of the precursor, or (2) $0.05 \mathrm{ml}$ of the respective alcohol (depending from precursor) and $0.01 \mathrm{ml}$ of $\mathrm{H}_{2} \mathrm{O}$ were added consequently by syringe on shaking to $0.5 \mathrm{ml}$ of toluene solution of the precursor. Directly after addition of water a milky colloid solution was obtained with 
following formation of nanobeads in both cases. The particles were separated by centrifugation with subsequent removal of solvent by decantation and dried in vacuum.

Starting solutions for preparation of nanobead samples were obtained by dissolution of $1.017 \mathrm{~g}$ of (I) in $7 \mathrm{ml}$ toluene, for the synthesis of $\mathbf{N B I}, \mathbf{N B I}^{*}$ and $\mathbf{N B I} \mathbf{I}^{* *}$ respectively (the first sample originating from natural hydrolysis, the one marked with one star - from forced hydrolysis with pure water and the one with two stars - from forced hydrolysis by water in parent alcohol); 0.121 $\mathrm{g}$ of (III) in $3 \mathrm{ml}$ toluene were used for NBIII, NBIII* and NBIII**; $0.294 \mathrm{~g}$ of (IV) in $4.8 \mathrm{ml}$ toluene were used for NBIV, NBIV* and NBIV**; and $0.719 \mathrm{~g}$ of (VI) in $2 \mathrm{ml}$ toluene were used for the synthesis of NBVI and NBVI*. Poor solubility of precursors (II) and (V) hinder preparation of the corresponding nanobead materials from them.

\section{Results and discussion}

\section{Precursor compounds}

Introduction of perrhenate anions into the structures of alkoxide precursors was achieved by a simple procedure involving refluxing of the commercially available metal alkoxides with rhenium(VII) oxide, $\mathrm{Re}_{2} \mathrm{O}_{7}$, taken in stoichiometric amounts. The reaction follows practically quantitatively the general scheme:

\section{$2 \mathrm{M}_{2}(\mathrm{OR})_{10}+\mathrm{Re}_{2} \mathrm{O}_{7} \longrightarrow \mathrm{M}_{4} \mathrm{O}_{2}(\mathrm{OR})_{14}\left(\mathrm{ReO}_{4}\right)_{2}+$ organic byproducts}

$$
M=\mathrm{Nb}, \mathrm{Ta} ; \mathrm{R}=\mathrm{Me}, \mathrm{Et}, \mathrm{n}-\mathrm{Pr}
$$

The structures of all synthesized complexes (see Fig. 1) are following the same structure type based on a tetranuclear $\mathrm{M}_{4}(\mu-\mathrm{O})_{2}(\mu-\mathrm{OR})_{4} \mathrm{X}_{12}$ core, $\mathrm{X}=\mathrm{OR}, \mathrm{ReO}_{4}$, with rectangular planar $\mathrm{M}_{4}{ }^{-}$ arrangement, composed of two pairs of edge-sharing octahedra, joined via two almost linear oxobridges. The perrhenate ligands are attached in a centrosymmetric manner to the two opposite 
corners of the rectangle and are thus incorporated in the coordination spheres of the transition metal $(\mathrm{Nb}, \mathrm{Ta})$ atoms of the alkoxide precursor.

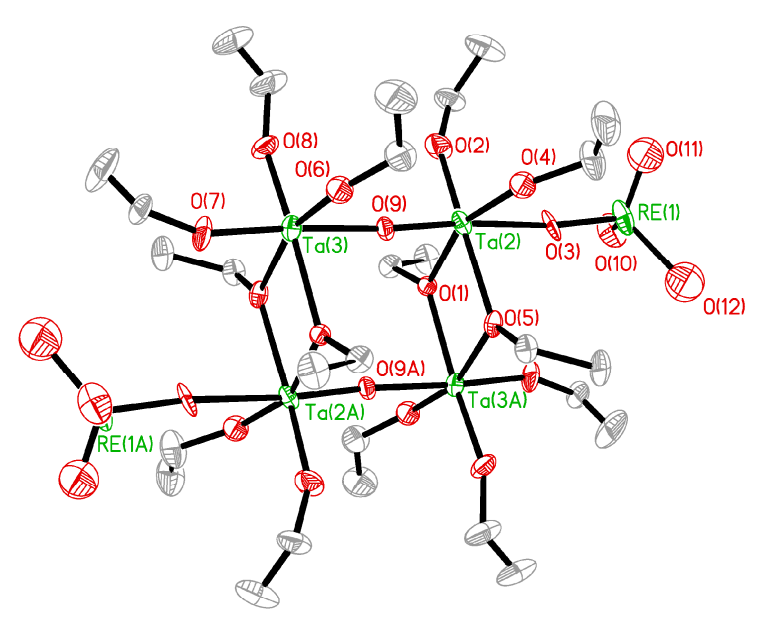

a

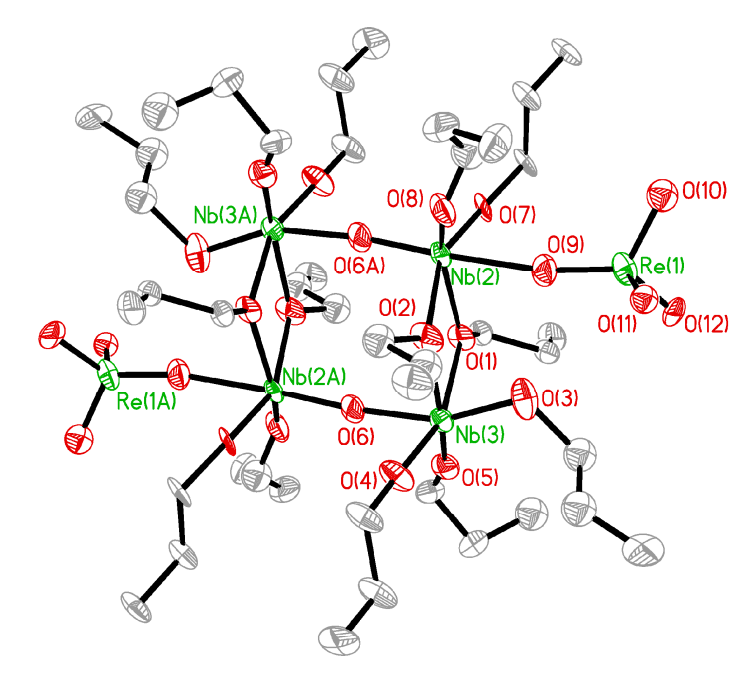

$\mathrm{b}$

Fig. 1 Ortep view of the molecular structures of $a-$ (I) and b - (III), representative for the precursor complexes.

It should be mentioned that the structures of trimetallic complexes (I) and (II) have non uniform distribution of niobium and tantalum between the two symmetrically independent positions. As it was described previously ${ }^{20}$ for the methoxide complex (II) the niobium atoms (70\%) preferably 
are situated in the oxo-position which is connected with perrhenate group in contrast to tantalum ones $(30 \%)$ which are more abundant in the alkoxo-position where $70 \%$ of tantalum atoms and $30 \%$ of niobium ones are present. The same tendency can be seen in the new ethoxocomplex (I), but the distribution of niobium and tantalum atoms is even more preferential: in oxo-position M1 is situated $85 \%$ of niobium and $15 \%$ of tantalum atoms while in alkoxo-position $\mathbf{M} 235 \%$ of $\mathrm{Nb}$ and $65 \%$ of Ta are present. According to the structure refinement statistics the ratio between $\mathrm{Nb}$ and $\mathrm{Ta}$ in the $\left(\mathbf{N b}_{\mathbf{x}} \mathbf{T a}_{1-\mathbf{x}}\right)_{\mathbf{4}} \mathbf{O}_{\mathbf{2}}(\mathbf{O E t})_{\mathbf{1 4}}\left(\mathbf{R e O}_{4}\right)_{2}$ complex is 60:40, while for the trimetallic methoxide complex (II) this ratio is 50:50. To confirm the ratios of $\mathrm{M}: \mathrm{Re}(\mathrm{M}=\mathrm{Nb}, \mathrm{Nb}+\mathrm{Ta})$ and $\mathrm{Nb}: \mathrm{Ta}$ in the bulk samples the EDS analysis has been performed (See table TS2).

The increasing size of the alkoxide ligand influences also the $\mathrm{M}-\mathrm{O}$ bond energy, which is confirmed by analysis of the IR spectra (see Table TS3). They show that the peaks shift toward smaller wavenumbers, which indicated that the interaction energy in case of trimetallic (I) and tantalum-rhenium bimetallic ethoxides (VI) is lower than in methoxo complexes (II) and (VII) respectively. In case of niobium-rhenium bimetallic complexes the same trend can be observed for the difference between the normal propoxide and ethoxide and methoxide respectively. In agreement with the earlier observations ${ }^{21 \mathrm{a}, 21 \mathrm{~b}}$, the bond lengths increase in the series: $\mathrm{r}(\mathrm{Re}-\mathrm{O})$ term $<\mathrm{r}(\mathrm{Re}-\mathrm{O}) \mu<\mathrm{r}(\mathrm{M}-\mathrm{OR})$ term $<\mathrm{r}(\mathrm{M}-\mathrm{O}) \mu<\mathrm{r}(\mathrm{M}-\mathrm{OR}) \mu<\mathrm{r}(\mathrm{M}-\mathrm{O}-\mathrm{Re}) \mu$.

\section{Nanobeads}

Following the hypothesis that application of perrhenate anions will improve stability of primary particles, originating from hydrolysis of metal alkoxides, and permit their more uniform aggregation, the solutions of perrhenate alkoxides were first subjected to slowly diffusing moisture via the procedure of natural hydrolysis.

For all the tested precursors it produced mostly spherical beads with different degree of aggregation. Relatively small fraction of bigger poorly shaped aggregates was also present. The 
size of the spheres was mostly uniform and showed no trend in relation to either nature of the alkoxide ligand or to concentration of the precursor solution.

The sample NBI reveal almost the same size of well-shaped spheres approximately $500-700 \mathrm{~nm}$ in average (see Fig $2 \mathrm{a}$ and $2 \mathrm{~b}$ ), mostly not aggregated. In case of spherical particles from the bimetallic precursors we can see that Niobium-containing ones distinctly are not uniform and have different size starting from $1 \mu \mathrm{m}$ and up to more than $40 \mu \mathrm{m}$. The Tantalum-containing sample NBVI shows well-formed, practically uniform particles $500 \mathrm{~nm}$ to $2 \mu \mathrm{m}$ in size, even when the solution concentration is quite high. It should be noticed that all nanobeads have dense oxide surface based on $\mathrm{Nb}$ or/and $\mathrm{Ta}$ metal oxides, resulting in very low active surface as measured by nitrogen sorption.
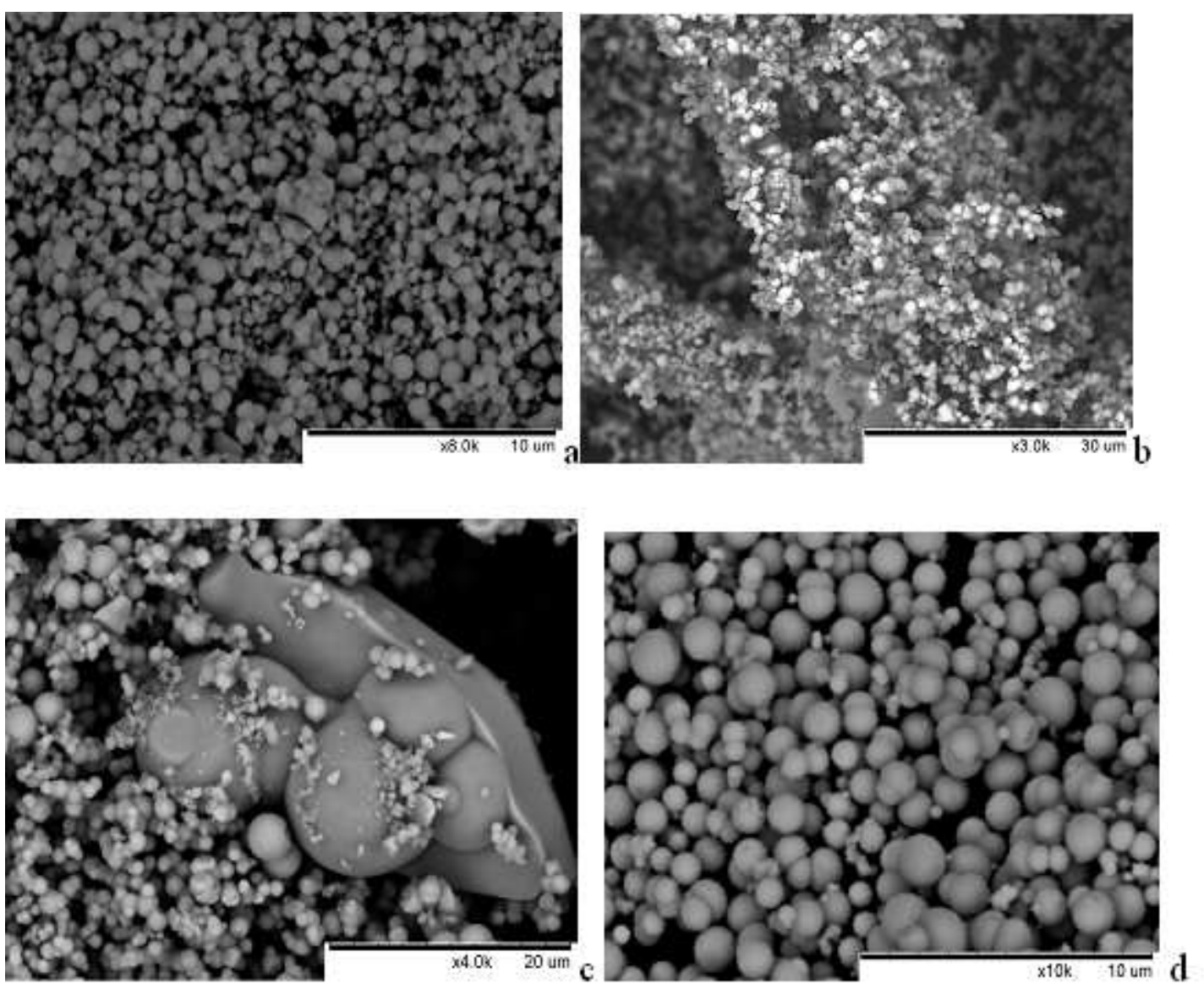

Fig. 2 SEM images of nanobeads obtained by natural hydrolysis: $\mathrm{a}-\mathbf{N B I}, \mathrm{b}-\mathbf{N B I I I}, \mathrm{c}-\mathbf{N B I V}$, d - NBVI 
The perrhenate ligand was quantitatively retained through the hydrolysis procedure according to the EDS analysis (see Tab. 1), which indicated the absence of hydrolysis for the M-O-Re bond and potential for their use as structure-directing units.

Table 1 Results of the EDS analysis for produced nanobeads

\begin{tabular}{|c|c|c|c|c|c|}
\hline \multirow[t]{2}{*}{ Nanobeads } & \multicolumn{3}{|c|}{ Atomic \% } & \multirow[t]{2}{*}{ Ratio Nb:Ta } & \multirow{2}{*}{$\begin{array}{c}\text { Ratio M:Re } \\
\qquad \begin{array}{l}\text { M=Nb } \\
\text { or/and Ta }\end{array}\end{array}$} \\
\hline & $\mathbf{N b}$ & Ta & $\operatorname{Re}$ & & \\
\hline NBI & 46.42 & 23.67 & 29.91 & $0.66: 0.34$ & $2.3: 1$ \\
\hline NBI* & 42.49 & 27.80 & 29.54 & $0.60: 0.40$ & $2.4: 1$ \\
\hline NBI** & 47.85 & 23.20 & 28.95 & $0.67: 0.33$ & $2.5: 1$ \\
\hline NBIII & 69.52 & & 30.48 & & $2.3: 1$ \\
\hline NBIII* & 67.55 & & 32.45 & & $2.1: 1$ \\
\hline NBIII** & 65.59 & & 34.41 & & $1.9: 1$ \\
\hline NBIV & 70.19 & & 29.80 & & $2.4: 1$ \\
\hline NBIV* & 71.03 & & 28.97 & & $2.5: 1$ \\
\hline NBIV** & 70.62 & & 29.37 & & $2.4: 1$ \\
\hline NBVI & & 61.99 & 38.01 & & $1.6: 1$ \\
\hline NBVI* & & 63.21 & 36.79 & & $1.7: 1$ \\
\hline NBVI** & & 63.93 & 36.07 & & $1.8: 1$ \\
\hline
\end{tabular}

Retention of perrhenate ligands is clearly observed from the FTIR spectra, where the M-O-Re frequencies are situated at practically same wavelength at $700-800 \mathrm{~cm}^{-1}$ as in the initial precursors and have quite strong intensity, while the frequencies, corresponding to the organic ligands, strongly decrease (see Tab. 2). In the IR spectra the characteristic bands at $400-650$ $\mathrm{cm}^{-1}$ could be assigned to $\mathrm{Nb}(\mathrm{Ta})-\mathrm{O}-\mathrm{Nb}(\mathrm{Ta})$ vibrations, corresponding to the bridging bonds 
analogous to those in the spectra of precursor complexes (see table TS 2). The characteristic set $\mathrm{Re}=\mathrm{O}$ bands indicate that $\mathrm{Re}$ is present in the beads as $\mathrm{ReO}_{4}$-ligands .

The coordination of the metal centers does not change during the hydrolysis as indicated by the EXAFS spectra (Fig. S7-S10), remaining octahedral for $\mathrm{Ta}(\mathrm{Nb})$ and tetrahedral (conservation of the perrhenate ligand structure) for Re.

Table 2 Comparison of the FTIR spectra* of the nanobeads obtained by natural hydrolysis $\mathrm{M}=\mathrm{Nb}$ or/and $\mathrm{Ta}$

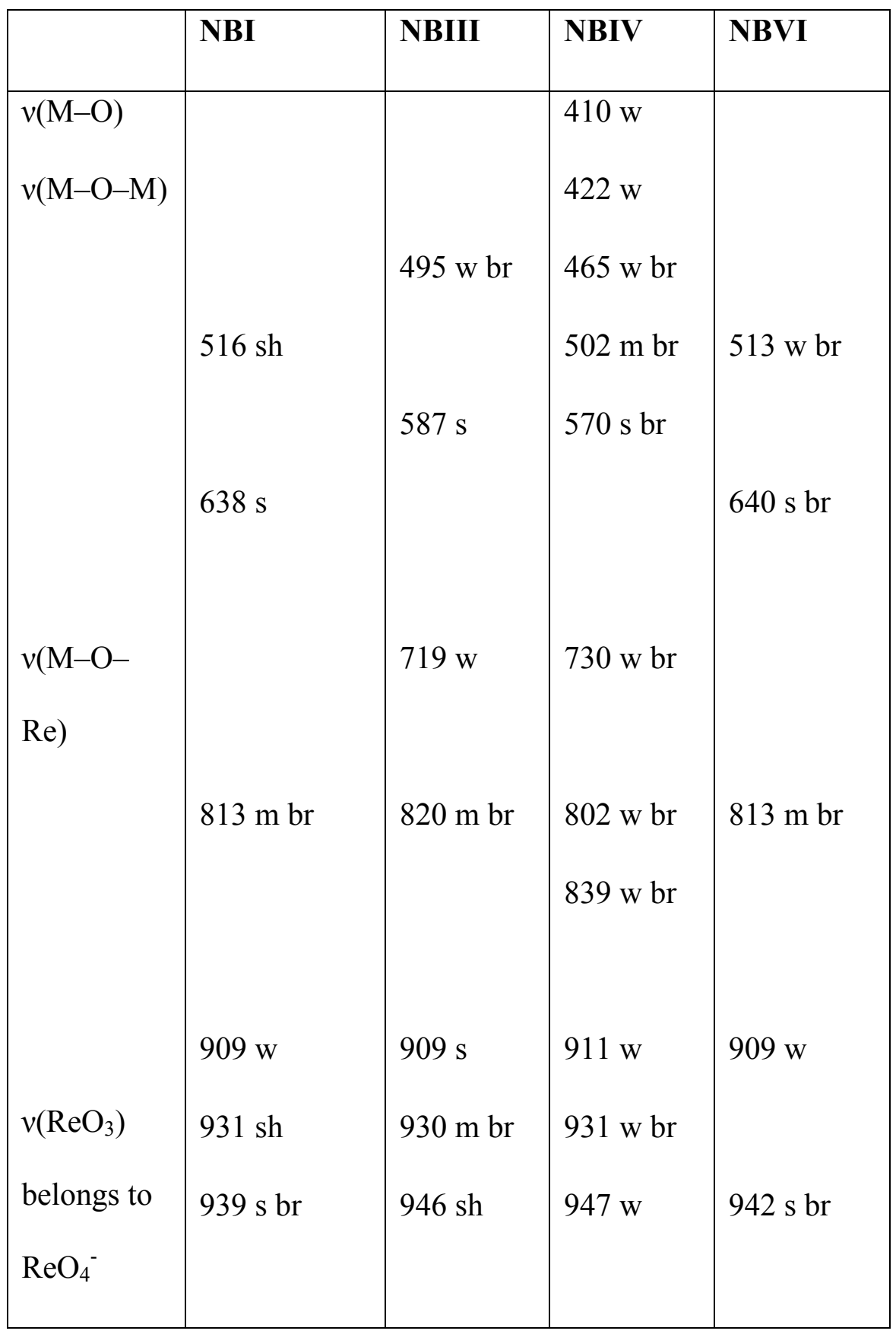


* s - strong, $\mathrm{w}$ - weak, br - broad, sh - shoulder

The forced hydrolysis is resulting in the formation of spherical particles with size and degree of aggregation strongly dependent on the polarity of the solvent (see Fig. 3). The kinetics of aggregation of the initially formed primary particles was followed by laser reflection microscopy using NanoSight (NTA Version 2.1) instrument (see real-time video VS1 in the Supplementary). The initial particles with the size below $10 \mathrm{~nm}$ aggregated uniformly to spherical particles of several hundred $\mathrm{nm}$ in size within minutes. The aggregates can be split into initial small particles again by sonication in a standard ultrasound bath in $5 \mathrm{~min}$ and the re-aggregation can then be followed to occur reproducibly with formation of again same type spherical aggregates in the same time scale. This is an important evidence for the formation of the observed oxide particles through so called Micelle Templated by Self-Assembly of Ligands (MTSAL) mechanism ${ }^{10,15}$. 

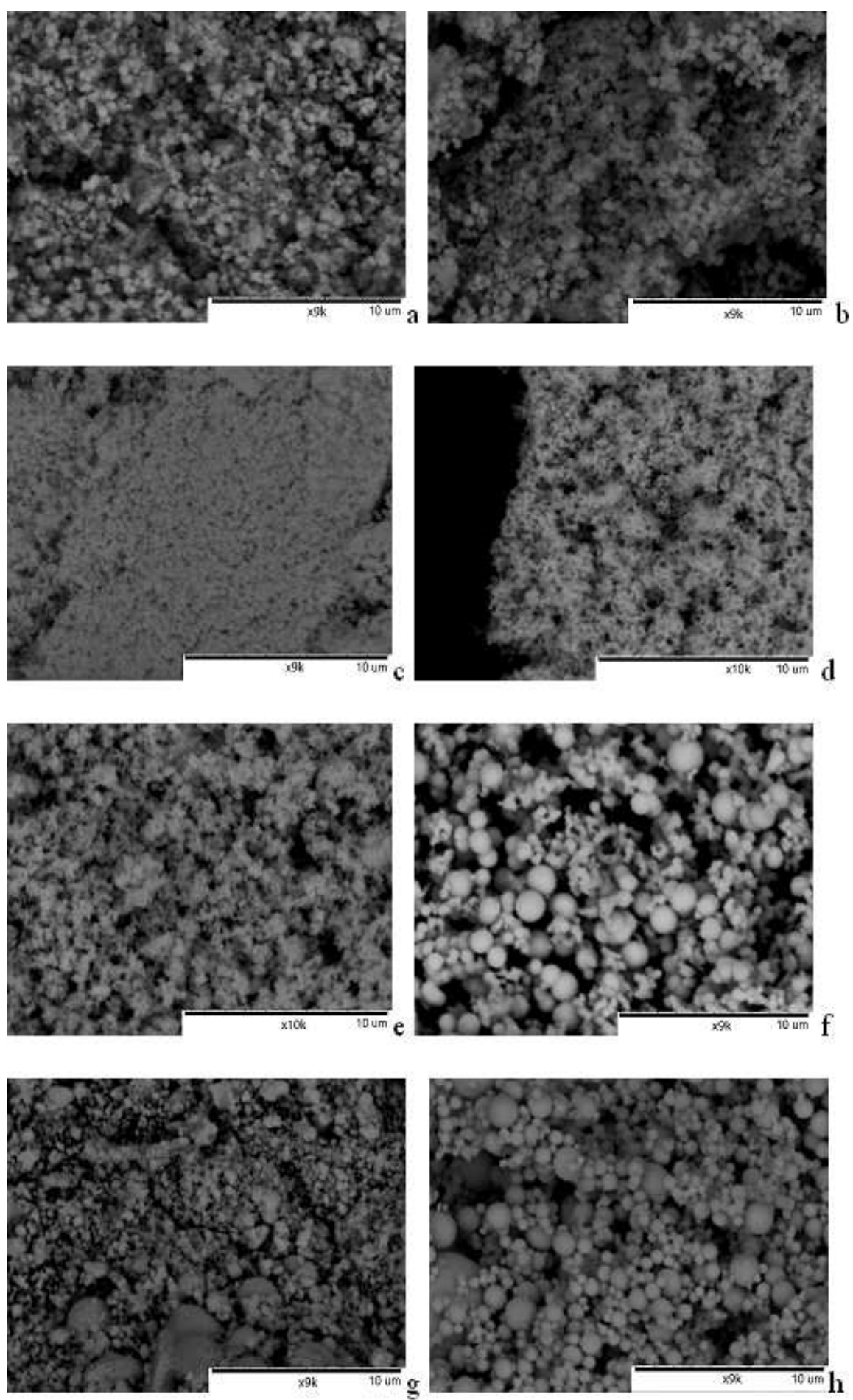

Fig. 3 SEM images of nanobeads obtained by forced hydrolysis: $a-$ NBI*$^{*}, \mathrm{~b}-\mathbf{N B I I}^{* *}, \mathrm{c}-$ NBIII* ${ }^{*} \mathrm{~d}-\mathbf{N B I I I}^{* *}, \mathrm{e}-\mathbf{N B I V} * \mathrm{f}-\mathbf{N B I V}^{* *}, \mathrm{~g}-\mathbf{N B V I}^{*}, \mathrm{~h}-\mathbf{N B V I}^{* *}$

As it can be seen from the figures $2 \mathrm{~b}, 2 \mathrm{~d}, 2 \mathrm{f}$ and $2 \mathrm{~h}$ the addition of the parent alcohol to the system leads to formation of better formed nanobeads, while the hydrolysis only with water results in the particles with the smaller size and less developed shape. The bigger aggregates are 
absent, because the coalescence of the primary particle occurs more uniformly as the distribution of water in the volume is more uniform due to agitation. Even in this case the retention of Re is complete and occurs in the form of $\mathrm{ReO}_{4}$-ligands according to EDS and FTIR.

In spite of well-defined geometry of the metal centers, the produced nanobeads remain amorphous on thermal treatment up to $700{ }^{\circ} \mathrm{C}$ even after $24 \mathrm{~h}$. Increasing the temperature to $1000^{\circ} \mathrm{C}$ leads to complete loss of $\mathrm{Re}$ (in the form of volatile $\mathrm{Re}_{2} \mathrm{O}_{7}$ ) with formation of crystalline nanobeads based on only $\mathrm{Nb}$ or/and Ta oxides (see Fig. 4). The surface area increases on this treatment considerably from less than $1 \mathrm{~m}^{2} / \mathrm{g}$ to about $1.2-4 \mathrm{~m}^{2} / \mathrm{g}$ according to the nitrogen sorption data (see FS9-FS10). The low value of the surface area observed indicate that the pores produced by removal of perrhenate anions in the form of volatile anhydride, $\mathrm{Re}_{2} \mathrm{O}_{7}$, are mostly cured at this high temperature, increasing only the surface roughness as observed in SEM (Fig.

4).
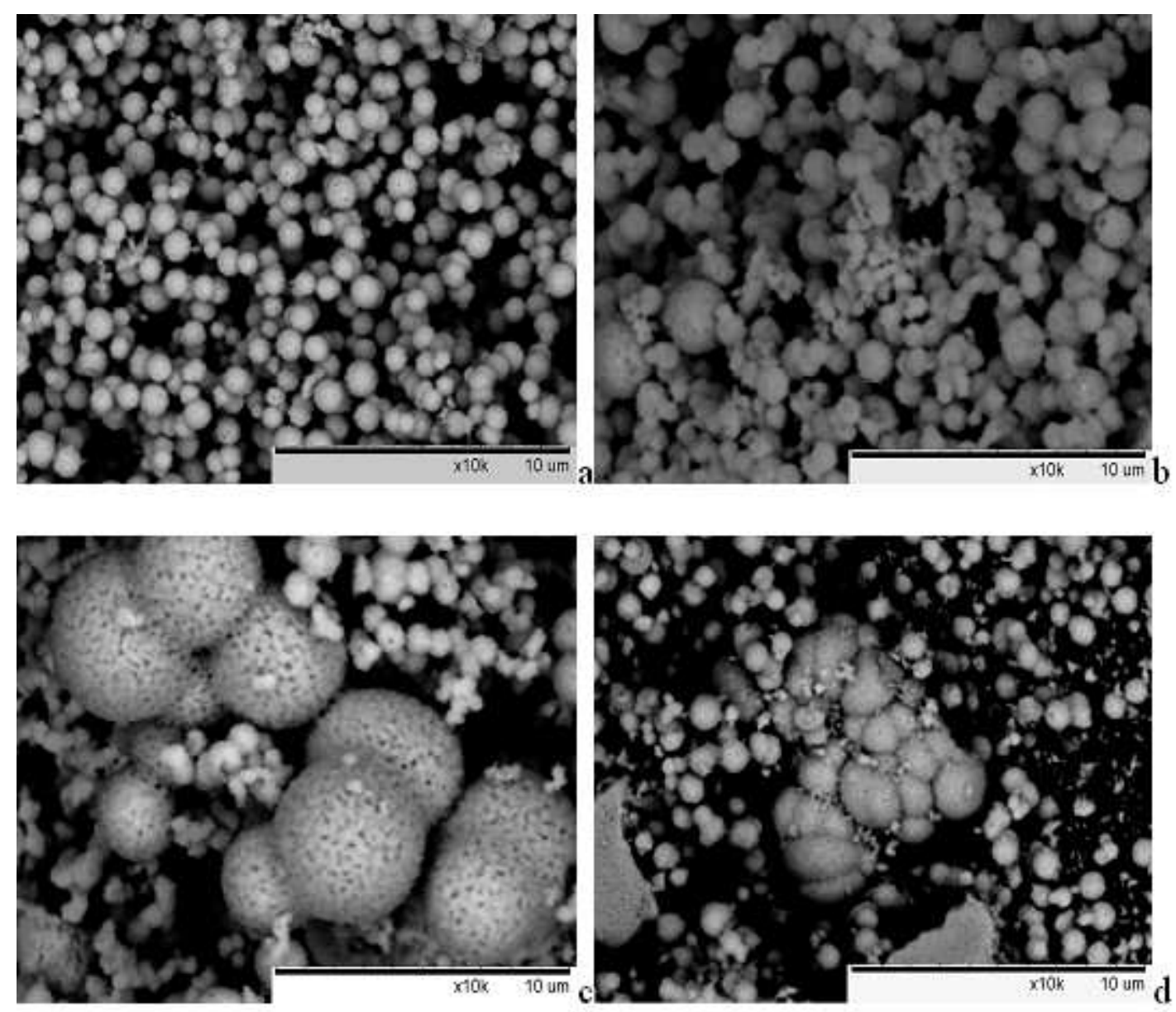

Fig. 4 SEM images of heat-treated nanobeads a - NBI, b - NBIII, $\mathrm{c}-\mathbf{N B I V}, \mathrm{d}-\mathbf{N B V I}$ 
The non-heat-treated beads are thus possessing fully dense surface (completely closed porosity) formed via coalescence of the original nanoparticles as it is often observed for the niobium and tantalum oxides produced by sol-gel. ${ }^{23}$ The products of thermal treatment were investigated by X-ray powder diffraction analysis (see Fig. 5). The XPD results have shown that NBIII and NBIV based on the monoclinic phase of $\alpha-\mathrm{Nb}_{2} \mathrm{O}_{5}$ oxide, for the samples of NBI and NBVI are resulting in formation of the orthorhombic modification of $\gamma-\mathrm{Ta}_{2} \mathrm{O}_{5}$ oxide.
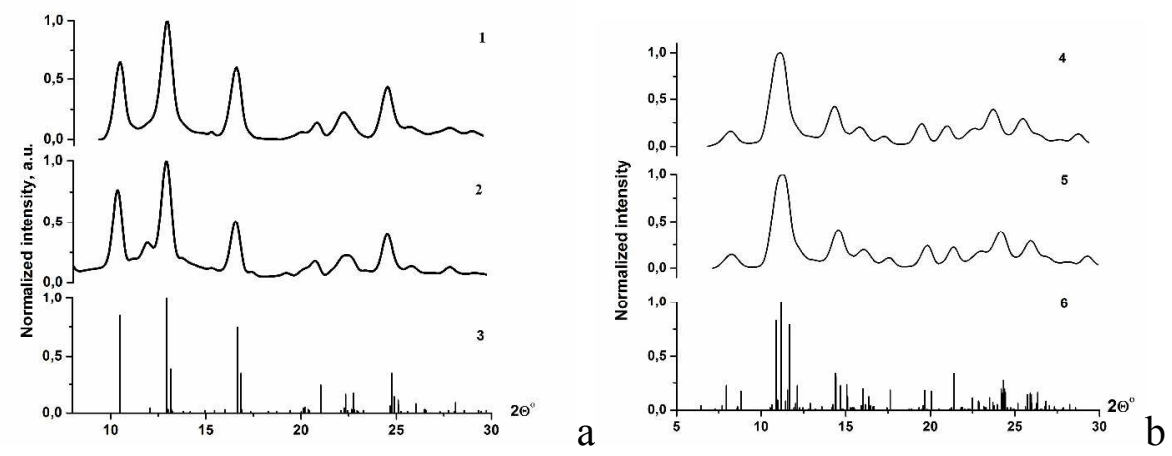

Fig. 5 XPD of the samples heat-treated at $1000^{\circ} \mathrm{C}$ a: $1-$ NBI, $2-$ NBVI, $3-\gamma-\mathrm{Ta}_{2} \mathrm{O}_{5}$ ICCDJCPDS 25-0922; b: 4 - NBIII, 5 - NBIV, 6 - $\alpha-\mathrm{Nb}_{2} \mathrm{O}_{5}$ ICCD- JCPDS 37-1468

Even if no Rietveld refinement of XPD patterns is performed we could add that the broad diffraction peaks observed are in good aggreement with nanocrystalline domains.

The EDS analysis indicated that the ratio between $\mathrm{Nb}$ and $\mathrm{Ta}$ in thermal product of NBI remains the same as in the initial sample NBI 65.98 and 34.02 at\% respectively.

In order to understand the mechanism guiding the self-assembly process, we have carried out DLS and $\zeta$ potential measurements on both the samples produced by forced hydrolysis by water and the products of their thermal treatment at $1000^{\circ} \mathrm{C}$. In all the cases the samples were dried in vacuum and re-dispersed in water by sonication. Because of rapid re-aglomeration of particles only aggreates size could be measured by DLS but all samples have been striclty measured in the same conditions (sonification conditions, time and delay after sonification). The results are summarized in Tab. 3 
Table 3. $\zeta$ potential and size of aggregates as observed by DLS measurements. The T-marking refers to the samples heat-treated at $1000^{\circ} \mathrm{C}$.

\begin{tabular}{|l|c|c|c|c|}
\hline Sample & $\zeta(\mathbf{m v})$ & Peak 1 r(nm) & Peak 2 r(nm) & $\begin{array}{c}\text { Integral intensity of the } \\
\text { main peak }\end{array}$ \\
\hline NBVI* & 34,6 & 548,1 & 0 & 0,594 \\
\hline NBVI*T $^{*}$ & $-2,78$ & 376,8 & 87,11 & 0,379 \\
\hline NBIII* $^{*}$ & $-9,31$ & 364,8 & 66,6 & 0,569 \\
\hline NBIII*T $^{*}$ & -23 & 309,1 & 2619 & 0,328 \\
\hline NBIV* $^{*}$ & 15,8 & 392,6 & 2746 & 0,318 \\
\hline NBIV*T $^{*}$ & $-27,2$ & 333,6 & 2515 & 0,285 \\
\hline NBI* $^{*}$ & 16,8 & 335,9 & 2780 & 0,600 \\
\hline NBI $^{*} \mathrm{~T}$ & $-29,4$ & 296,9 & 2633 & 0,388 \\
\hline
\end{tabular}

The observed sizes of the aggregates are in good agreement with the SEM data. The $\zeta$ potentials reveal a clear and consistent insight in the role of the introduced anion as a source for stabilization of surface charge, related also in turn to the acidity of the transition metal oxide. Generally, the presence of an anion in the inner coordination sphere of the atoms on the surface facilitates their ability to bear a positive charge. $\mathrm{Ta}_{2} \mathrm{O}_{5}$ is much less acidic (more basic) compound compared to $\mathrm{Nb}_{2} \mathrm{O}_{5}$, which explains much higher positive potential for NBVI* derived from $\mathbf{T a}_{\mathbf{4}} \mathrm{O}_{\mathbf{2}}(\mathrm{OEt})_{\mathbf{1 4}}\left(\mathrm{ReO}_{4}\right)_{\mathbf{2}}$ (VI) compared to all other samples. When the anions are removed by thermal treatment (in $\mathrm{NBVI}^{*} \mathrm{~T}$ ) the surface charge practically disappears and the aggregation and de-aggregation will only be due to hydrogen bonding on the surface. For the analogous ethoxide-derived samples $\mathrm{NBIV}^{*}$ and $\mathrm{NBI}^{*}$ (produced from $\mathbf{N b}_{\mathbf{4}} \mathbf{O}_{\mathbf{2}}(\mathbf{O E t})_{\mathbf{1 4}}\left(\mathbf{R e} \mathbf{O}_{4}\right)_{\mathbf{2}}$ (IV) and $\left(\mathrm{Nb}_{\mathbf{x}} \mathrm{Ta}_{1-\mathbf{x}}\right)_{\mathbf{4}} \mathrm{O}_{\mathbf{2}}(\mathrm{OEt})_{\mathbf{1 4}}\left(\mathrm{ReO}_{4}\right)_{\mathbf{2}}$ (I) respectively) the positive charge is lower due, apparently to higher acidity (lower basicity) of niobium oxide. When the ligands are removed in $\mathrm{NBIV}^{*} \mathrm{~T}$ and $\mathrm{NBI}^{*} \mathrm{~T}$, the particles gain distinct negative charge due to the same reason. The same trend is even visible for NBIII*, obtained from an n-propoxide complex, but the observed potential here is negative already for the non-heat-treated sample. The explanation for this deviation can be sought in the relative hydrophobicity of the residual n-propoxide ligands on the surface of the particles, influencing formation of the electric double layer. The thermal treatment 
removes all the surface ligands and offers distinctly negative charged particles as it should be observed for the appreciably acidic niobium oxide.

\section{Conclusions}

Application of perrhenate as structure-directing ligand permits successful and reproducible preparation of spherical particles conserving all of its Re content from small primary particles originating on hydrolysis of the alkoxide precursor. The self-assembly process is guided by a relative positive charge of the particles stabilized via inclusion of negatively charged perrhenate ligands into the coordination sphere of transition metal atoms on the surface. The aggregation can be reversed in solution by sonication, but the primary particles assemble again into spherical beads. The particles remain amorphous and retain $\mathrm{Re}$ until rather high temperatures $\left(700^{\circ} \mathrm{C}\right)$, most probably due to formation of dense oxide layer on their surface. The Re content is lost at $1000^{\circ} \mathrm{C}$ with resulting increase in surface roughness as observed by SEM.

Supplementary materials available: Details of synthesis, spectroscopic and crystallographic characterization for molecular precursors applied, results of FTIR, EXAFS, TEM, nitrogen adsorption studies, a real-time movie demonstrating the aggregation process, and statistical description of the NanoSight measurements on the aggregation process for the produced nanobeads. This material is available free of charge via the Internet at http://pubs.acs.org.

\section{Acknowledgements}

Authors would like express their gratitude to Corine Sandström for performing the NMR experiment, to Suresh Gohil from Department of Chemistry, SLU, to Jonathan Smith from NanoSight Ltd for assistance with size distribution data collection on NBI, NBVI and to MAXlab for the giving time to perform the EXAFS data collection from Lund. 


\section{References}

1. Fan, H. Y.; Yang, K.; Boye, D. M.; Sigmon, T.; Malloy, K. J.; Xu, H. F.; Lopez, G. P.; Brinker, C., J. Science 2004, 304, 567-571.

2. Boal, A. K.; Ilhan, F.; DeRouchey, J. E.; Thurn-Albrecht, T.; Russell, T. P.; Rotello, V. M., Nature 2000, 404, 746-748.

3. Qiu, P.; Jensen, C.; Charity, N.; Towner, R.; Mao, C., J. of Amer. Chem. Soc. 2010, 132, 1772417732.

4. Yu, S. H.; Pucci, A.; Herntrich, T.; Willinger, M. G.; Baek, S. H.; Sung, Y. E.; Pinna, N., J. Mater. Chem. 2011, 21, 806-810.

5. Sauvage, F.; Chen, D.; Comte, P.; Huang, F.; Heiniger, L. P.; Cheng, Y. B.; Caruso, R. A.; Graetzel, M., ACS Nano 2010, 4 (8), 4420-4425.

6. Ahn, S. H.; Koh, J. H.; Seo, J. A.; Kim, J. H., Chem. Comm. 2010, 46, 1935-1937.

7. Lu, P. J.; Zaccarelli, E.; Ciulla, F.; Schofield, A. B.; Sciortino, F.; Weitz, D. A., Nature 2008, $453,499-504$.

8. Kessler, V. G.; Spijksma, G. I.; Seisenbaeva, G. A.; Håkansson, S.; Blank, D. H. A.; Bouwmeester, H. J. M., J. Sol-Gel Sci. Tech. 2006, 40, 163-179.

9. Kessler, V. G.; Seisenbaeva, G. A.; Håkansson, S.; Unell, M., Ang. Chemie Int.. Edition 2008, 47, 8506-8509.

10. Kessler, V. G., J. Sol-Gel Sci. Tech. 2009, 51, 264-271.

11. Chen, D. H.; Huang, F. Z.; Cheng, Y. B.; Caruso, R. A., Adv. Mater. 2009, 21, 2206-2210.

12. Baruwati, B.; Varma, R. S., Crystal Growth \& Design 2010, 10, 3424-3428.

13. Lee, B. J.; Yamashita, T.; Lu, D. L.; Kondo, J. N.; Domen, K., Chem. Mat. 2002, 14 (2), 867-875.

14. Lin, K. L.; Wang, H. C., J. Mater. Sci. 1988, 23, 3666-3670.

15. (a) Seisenbaeva, G. A.; Kessler, V. G.; Pazik, R.; Strek, W., Dalton Transact. 2008, 3412-3421;

(b) Kessler, V. G.; Spijksma, G. I.; Seisenbaeva, G. A.; Håkansson, S.; Blank, D. H. A.; Bouwmeeter, H. J. M., J. Sol-Gel Sci. Tech. 2006, 40, 163-179; (c) Seisenbaeva, G. A.; Moloney, M. P.; Tekoriute, R.; Hardy-Dessource, A.; Nedelec, J. M.; Gun’ko, Y. K.; Kessler, V. G., Langmuir 2010, 26, 9809-9817. 16. Jolivet, J.P.; Cassaignon, S.; Chanéac, C.; Chiche, D.; Durupthy, O.; Portehault, D., C.R. Chimie $2010,13,40-51$. 
17. Thompson, A.; Attwood, D.; Gullikson, E.; Howells, M.; Kim, K.-J.; Kirz, J.; Kortright, J.; Lindau, I.; Pianatta, P.; Robinson, A.; Scofield, J.; Underwood, J.; Vaughan, D.; Williams, G.; Winick, H. X-ray Data Booklet, Berkeley, California 94720, 2001.

18. George, G. N.; Pickering, I. J. EXAFSPAK - A Suite of Computer Programs for Analysis of X-Ray Absorption Spectra, Stanford, CA, 1993.

19. Turevskaya, E.P.; Turova, N. Y.; Korolev, A.V.; Yanovsky, A.I.; Struchkov, Yu.T., Polyhedron 1995, $14,1531-1542$.

20. Shcheglov, P.A.; Seisenbaeva, G. A.; Gohil, S.; Drobot, D.V.; Kessler, V.G., Polyhedron 2002, $21,2317-2322$.

21. (a) Nikonova, O. A.; Kessler, V. G.; Drobot, D.V.; Shcheglov, P. A.; Seisenbaeva, G. A., Polyhedron 2007, 26, 862-866; (b) Nikonova, O. A.; Seisenbaeva, G. A.; Kessler, V. G.; Shcheglov, P. A.; Drobot, D. V., Rus. J. Inorg. Chem. 2007, 52 (11), 1687-1693; (c) Seisenbaeva, G. A.; Shevelkov, A. V.; Tegenfeldt, J.; Kloo, L.; Drobot, D. V.; Kessler, V. G., Dalton Transact. 2001, 2762-2768.

22. Shcheglov, P. A.; Seisenbaeva, G. A.; Gohil, S.; Drobot, D. V.; Kessler, V. G., Polyhedron 2002, $21,2317-2322$.

23. Werndrup, P.; Verdenelli, M.; Chasseageux, F.; Parola, S.; Kessler, V.G., J. Mater. Chem. 2004, $14,344-350$. 


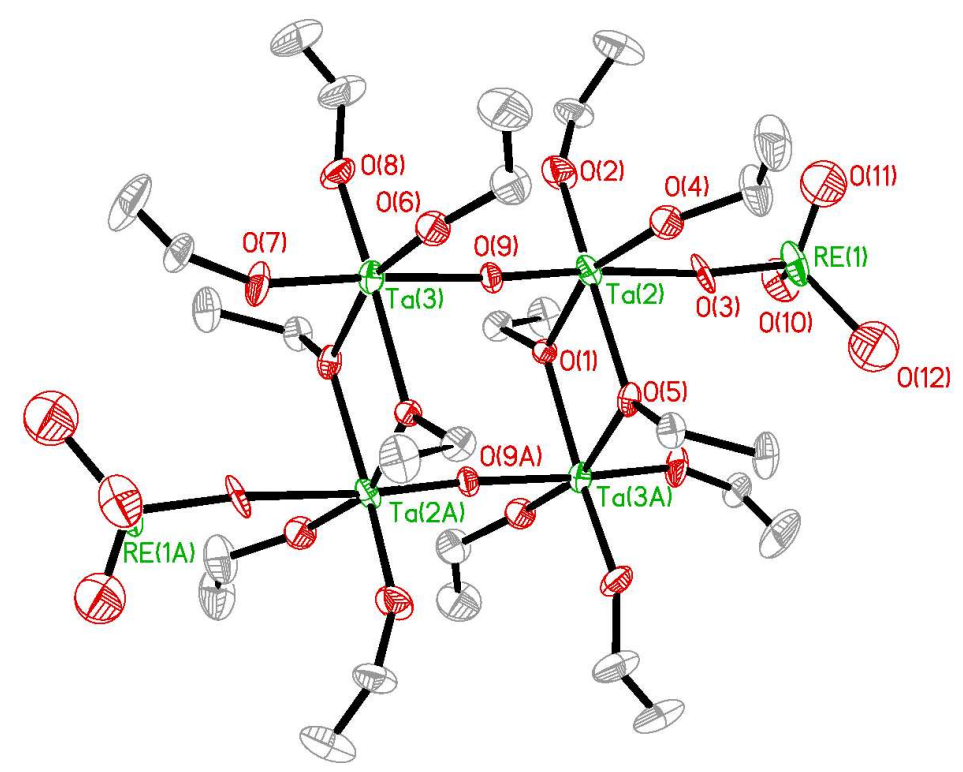

Ortep view...

$279 \times 215 \mathrm{~mm}(300 \times 300$ DPI $)$ 
2

3

4
5

6

7

8

10

11

12

13

14

15

16

17

18

19

20

21

22

23

24

25

26

27

28

29

30

31

32

33

34

35

36

37

38

39

40

41

42

43

44

45

46

47

48

49

50

51

52

53

54

55

56

57

58

59

60

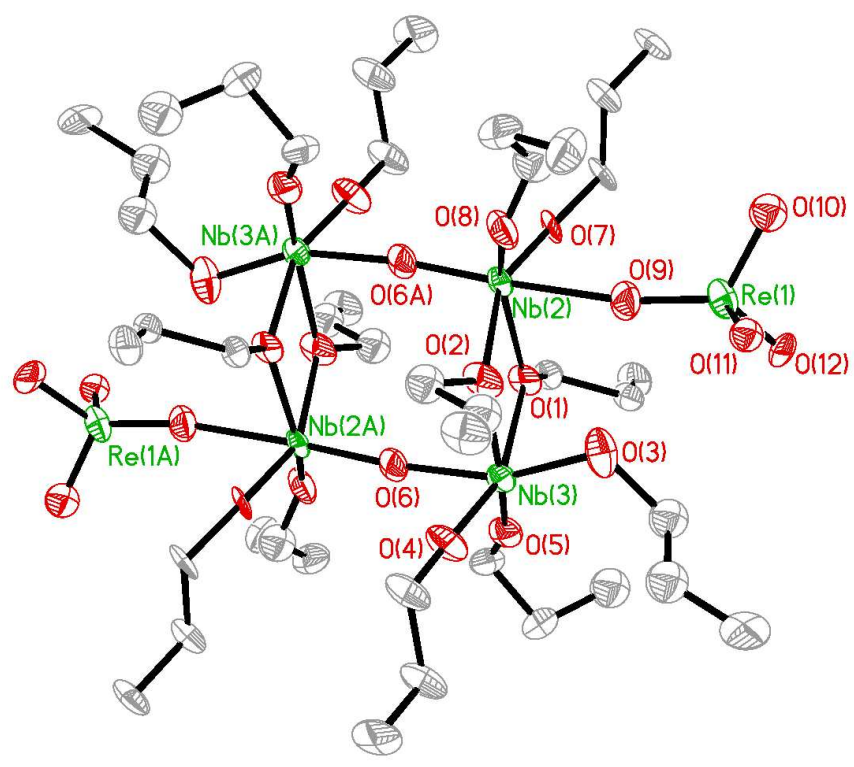

Ortep view..

$279 \times 215 \mathrm{~mm}(300 \times 300$ DPI $)$ 


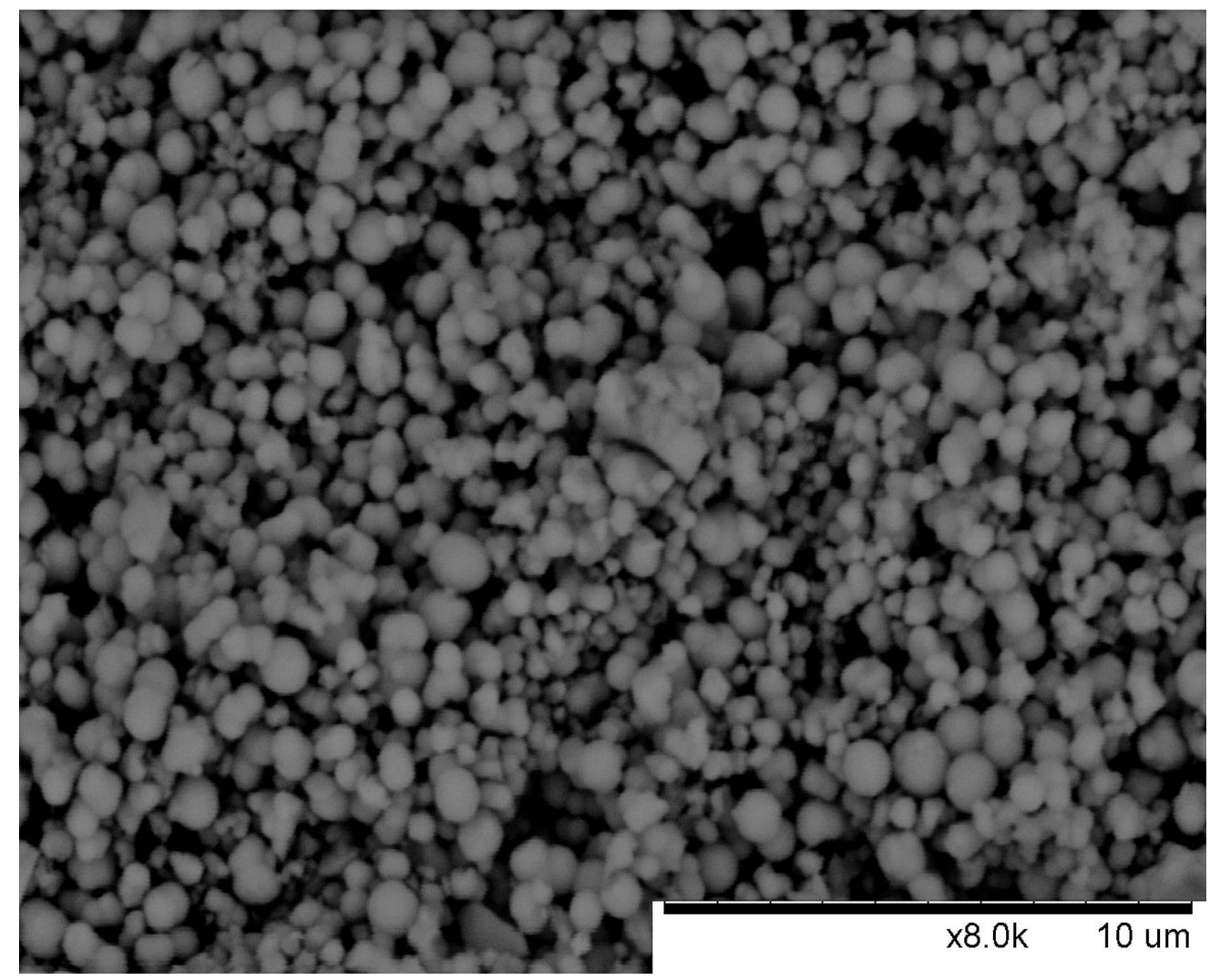

Obtained by natural hydrolysis from NBI $179 \times 145 \mathrm{~mm}(300 \times 300$ DPI $)$ 


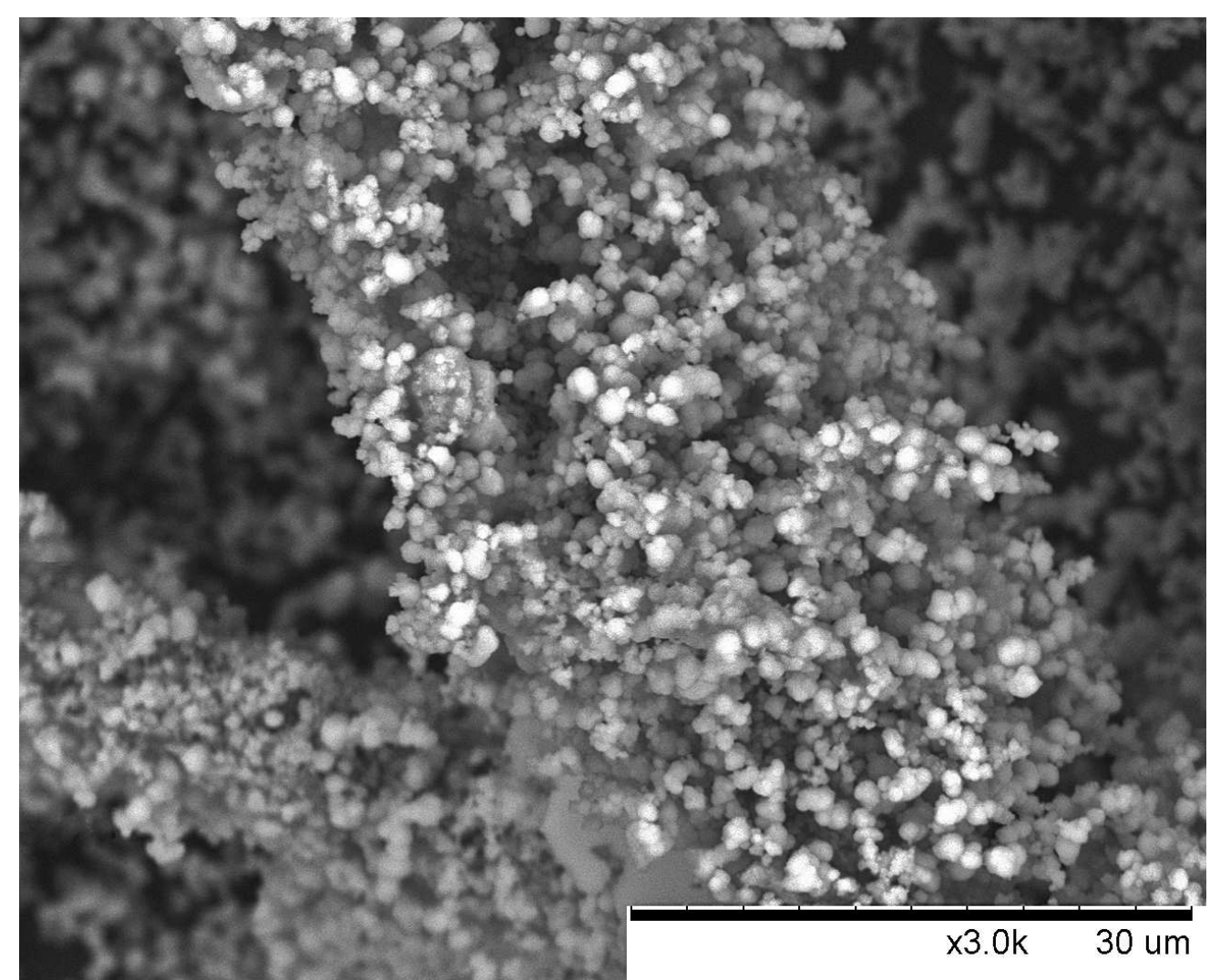

Obtained by natural hydrolysis from NBIII $190 \times 154 \mathrm{~mm}(171 \times 171 \mathrm{DPI})$ 


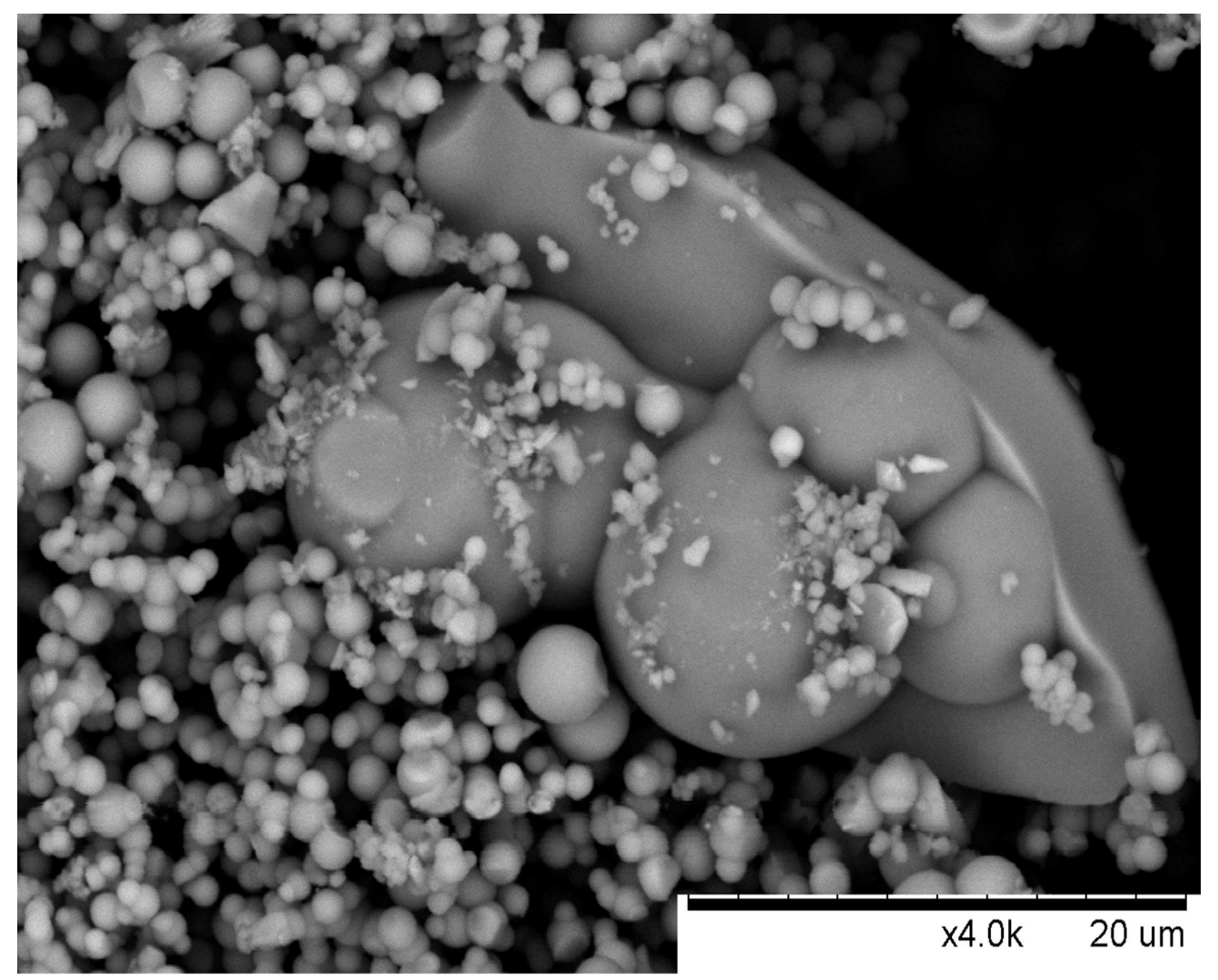

Obtained by natural hydrolysis from NBIV $190 \times 154 \mathrm{~mm}(300 \times 300$ DPI $)$ 


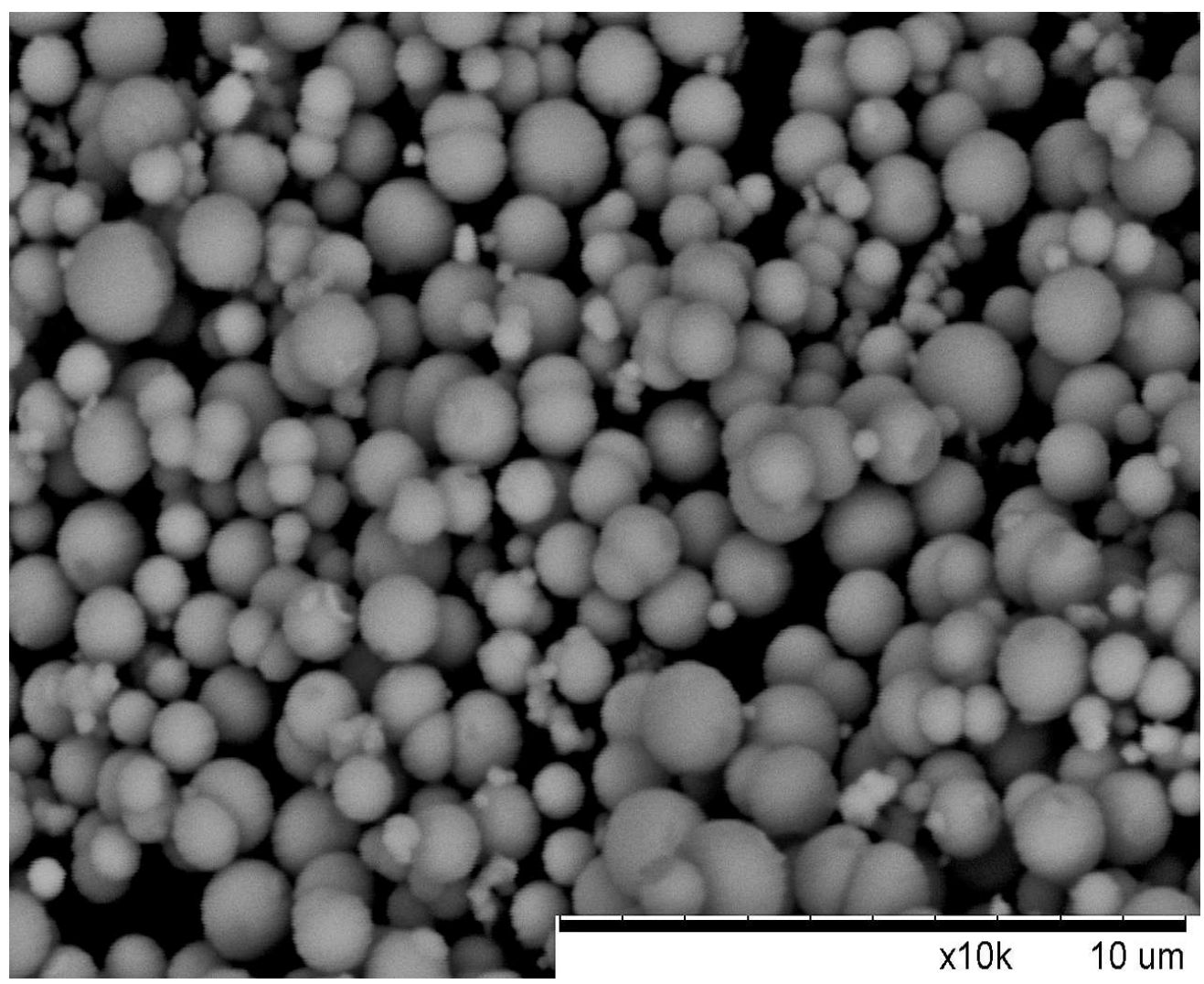

Obtained by natural hydrolysis of NBVI $190 \times 154 \mathrm{~mm}(171 \times 171 \mathrm{DPI})$ 


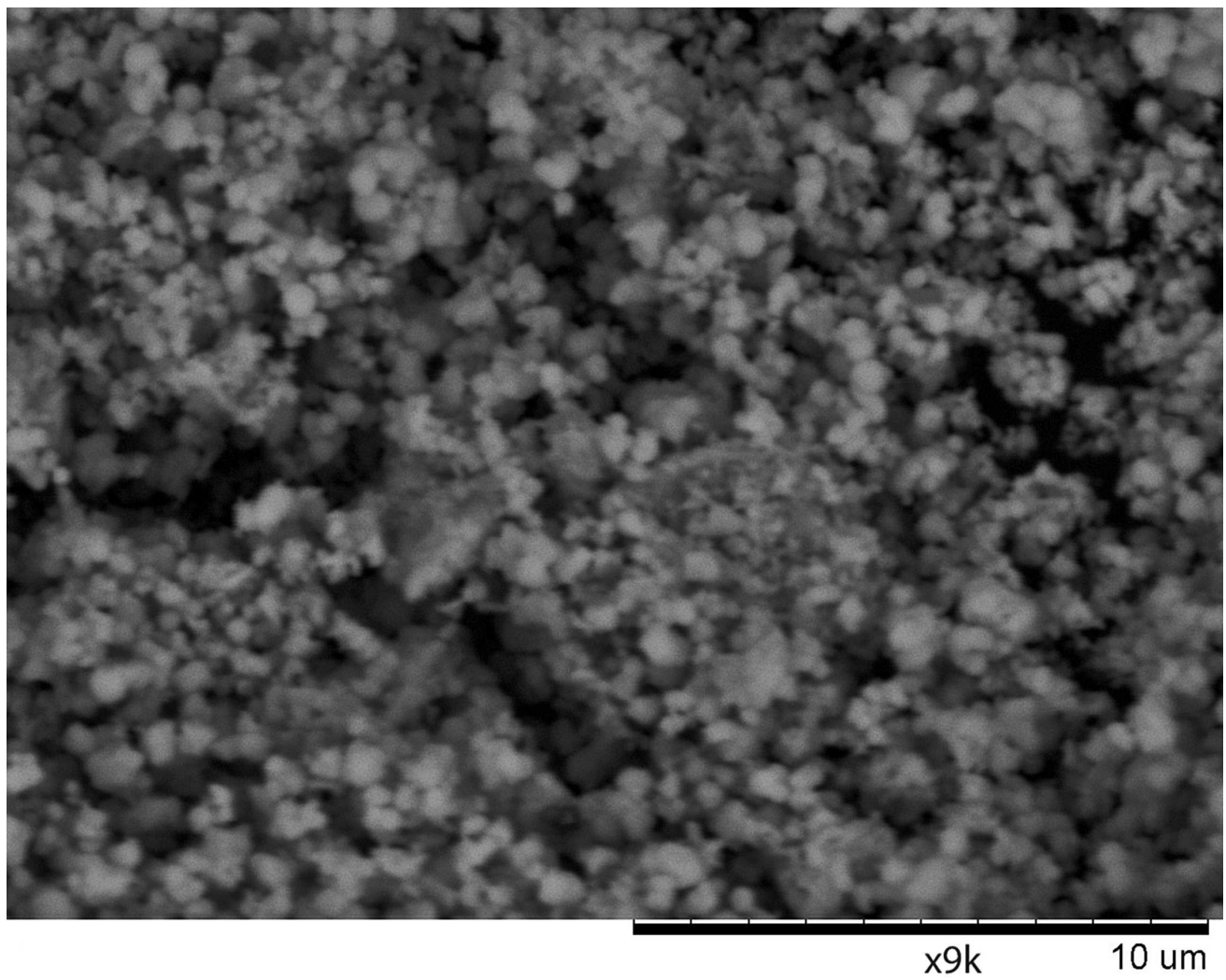

Obtained by forced hydrolysis of NBI* $190 \times 154 \mathrm{~mm}$ ( $300 \times 300$ DPI) 


\section{Page 27 of 39}

Langmuir

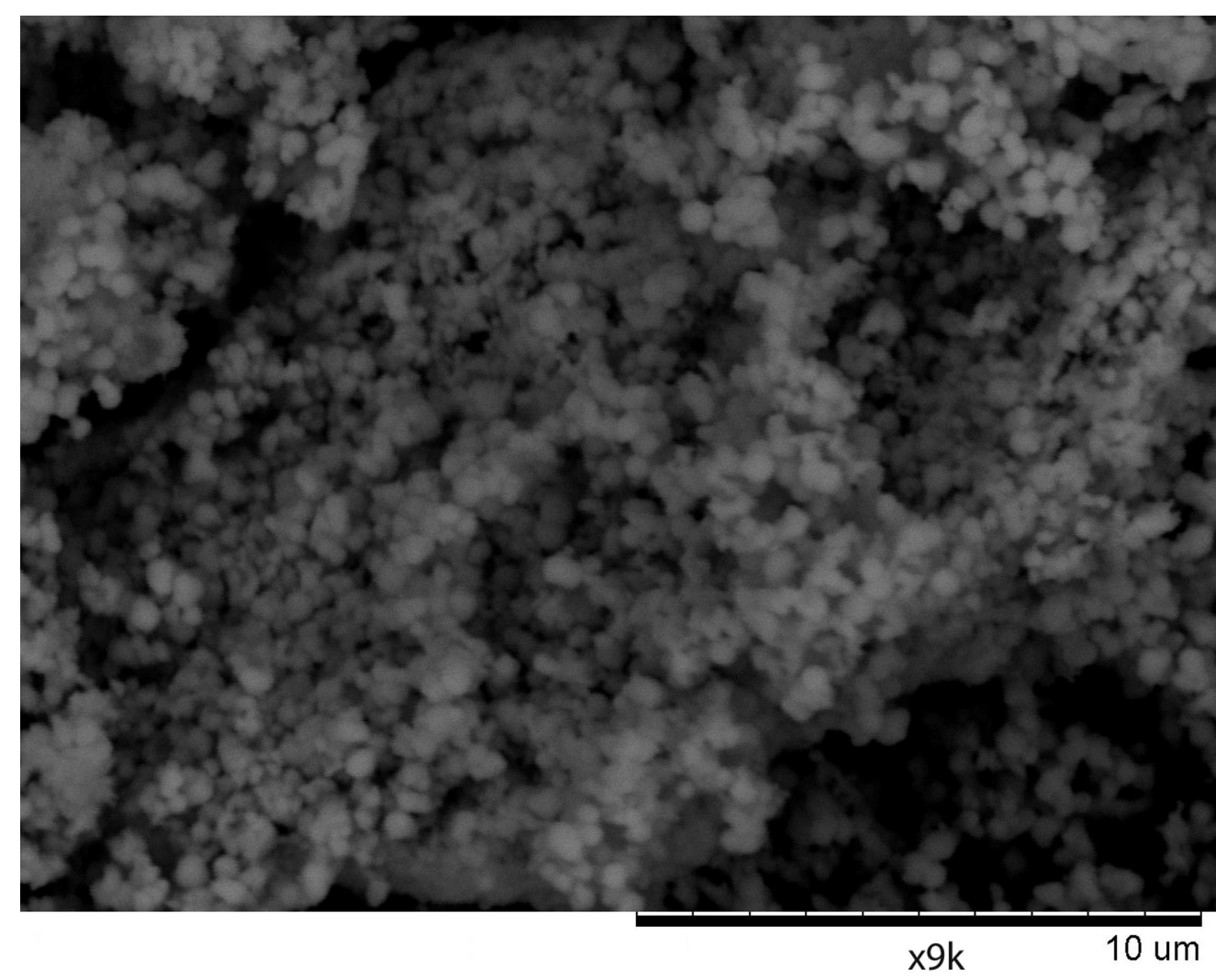

Obtained by forced hydrolysis of NBII* $190 \times 154 \mathrm{~mm}$ ( $300 \times 300 \mathrm{DPI})$
2

4

5

7

8

10

11

12

14

15

16

18

19

20

21
22

23

24

25

26

27

29

30

32

33

34

35

36

38

39

40

41

42

43

44

46

47

48

49

50

51

52

53

54

55

56

57

58

59 


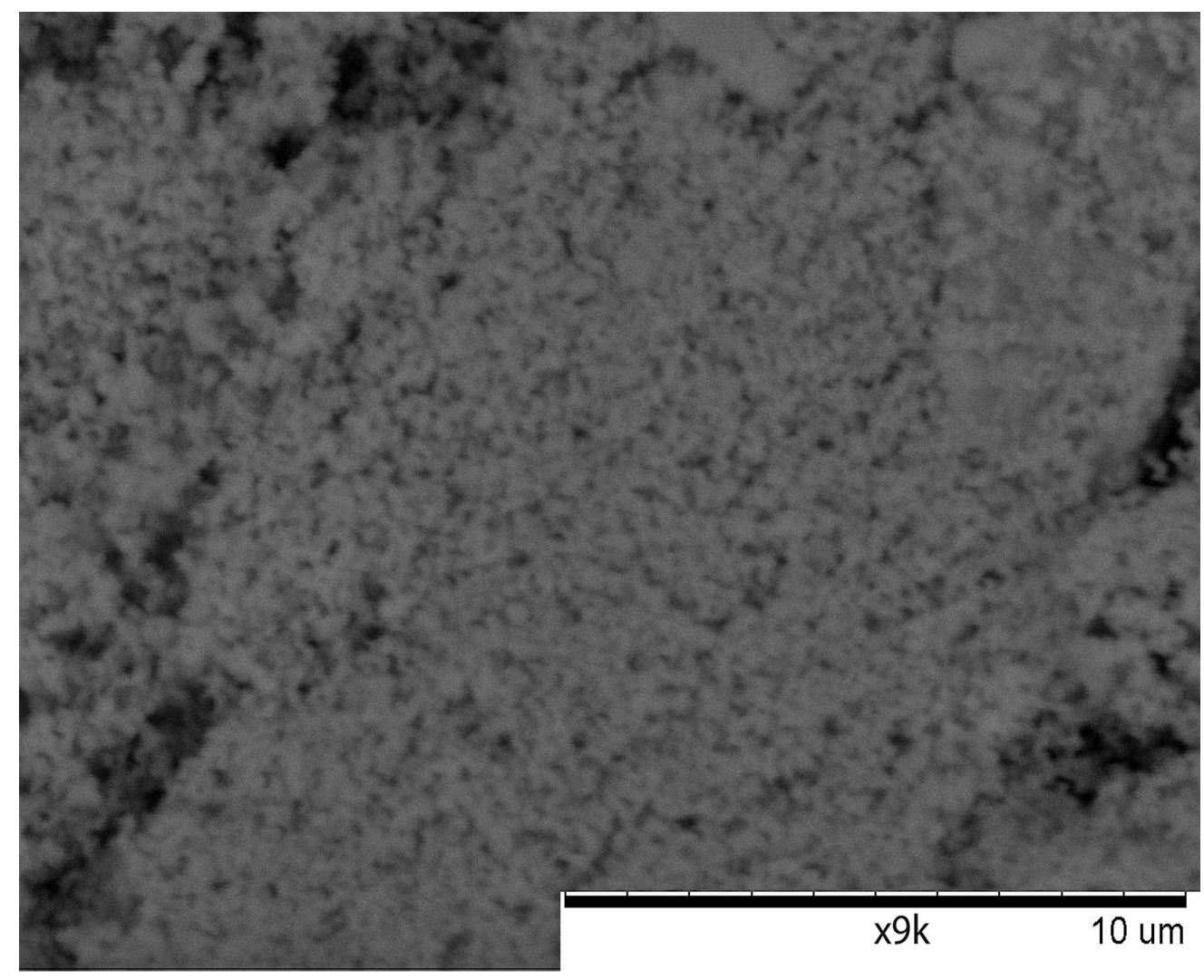

Obtained by forced hydrolysis of NBIII* $190 \times 154 \mathrm{~mm}(300 \times 300 \mathrm{DPI})$ 


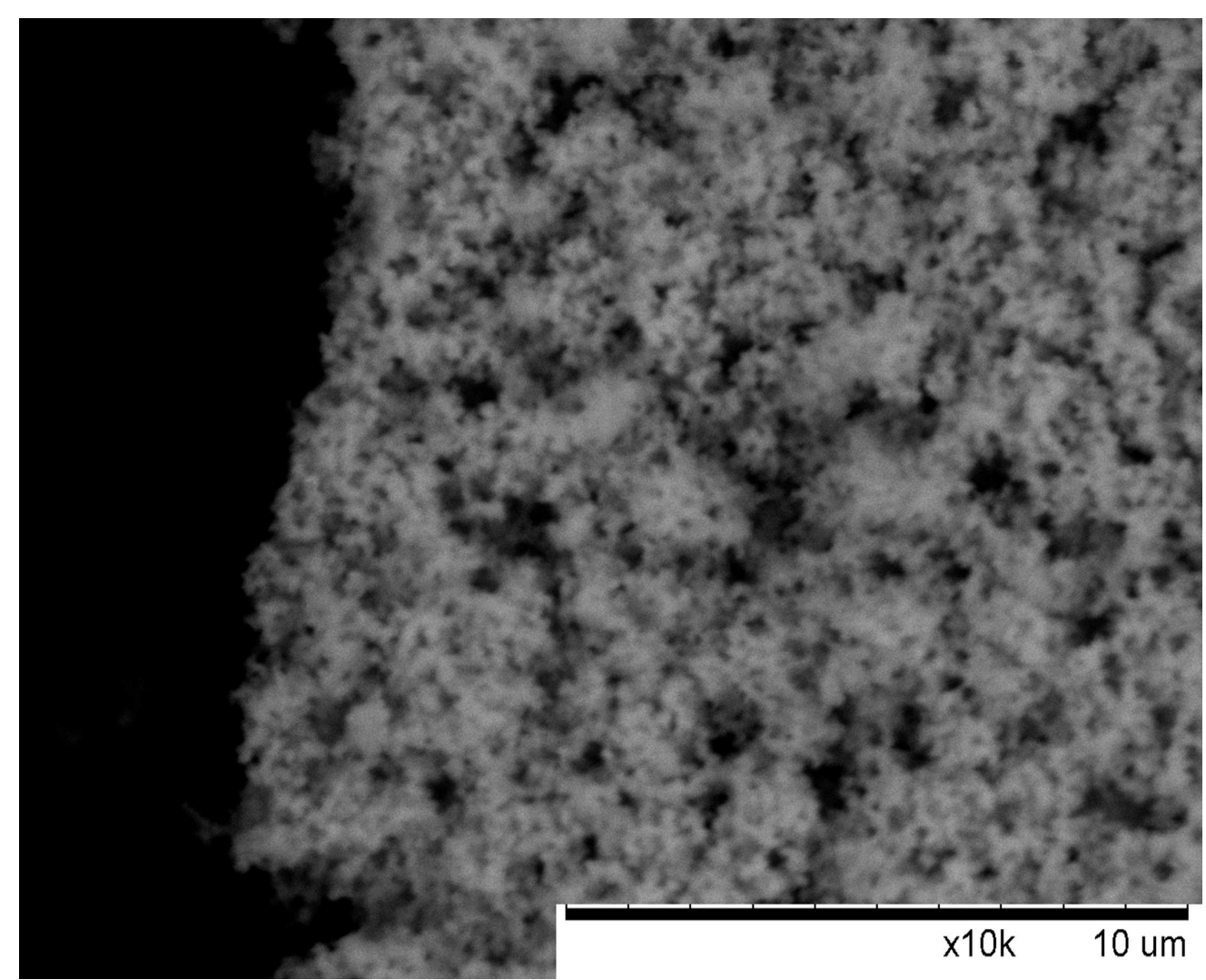

Obtained by forced hydrolysis of NBIII** $190 \times 154 \mathrm{~mm}(300 \times 300 \mathrm{DPI})$ 


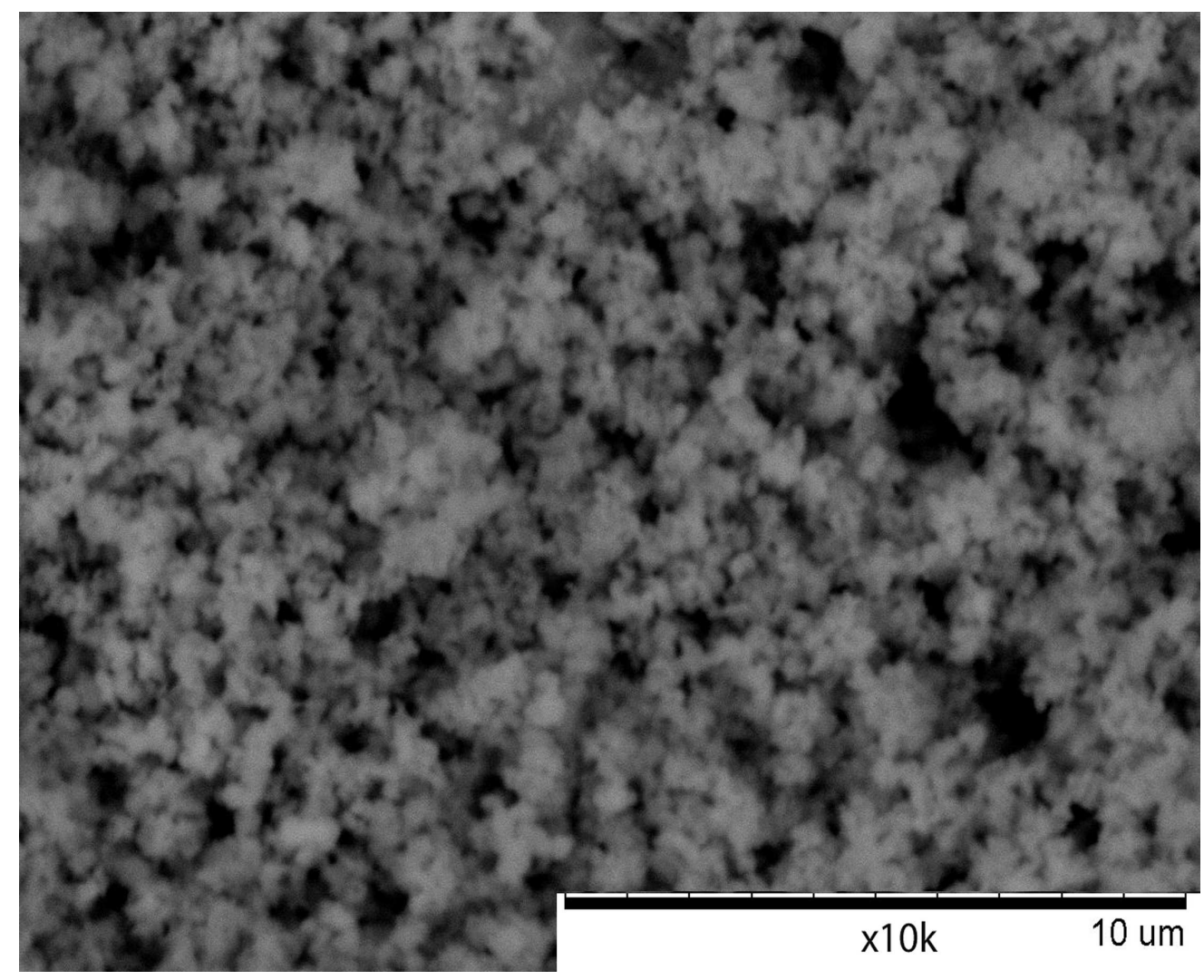

Obtained by forced hydrolysis of NBIV* $190 \times 154 \mathrm{~mm}(300 \times 300$ DPI $)$ 


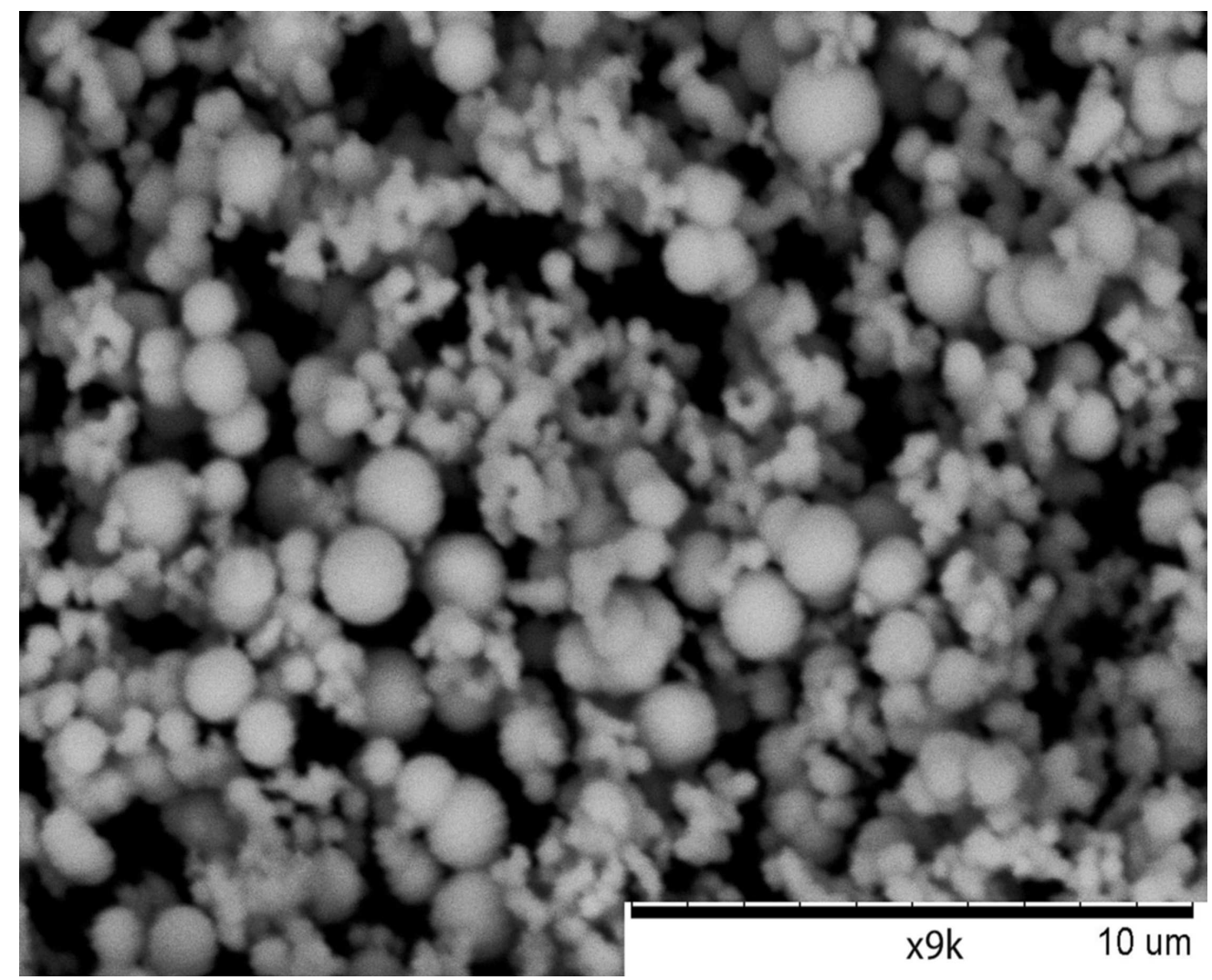

Obtained by forced hydrolysis of NBIV** $190 \times 154 \mathrm{~mm}(300 \times 300$ DPI) 


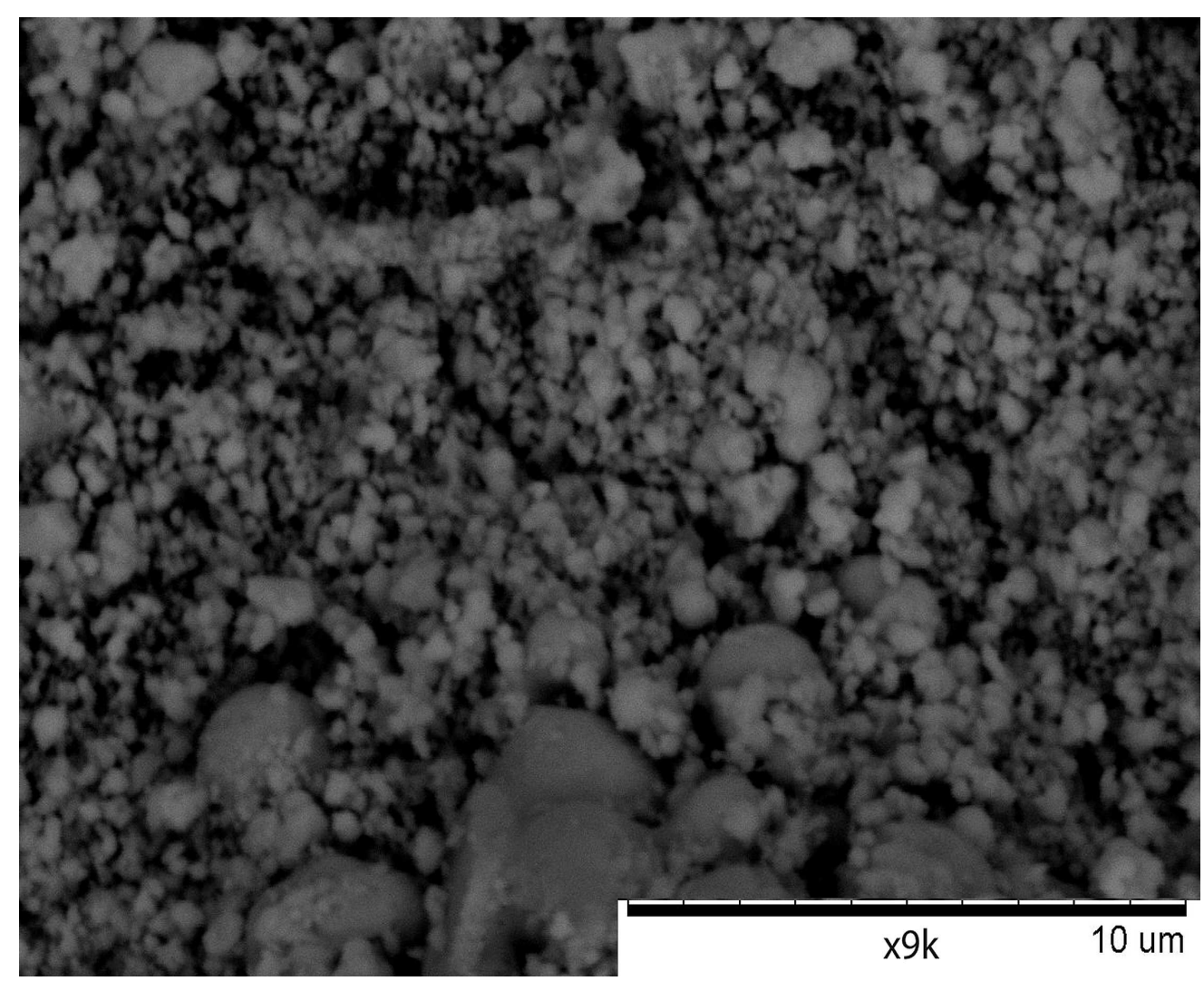

Obtained by forced hydrolysis of NBVI* $190 \times 154 \mathrm{~mm}(300 \times 300$ DPI) 


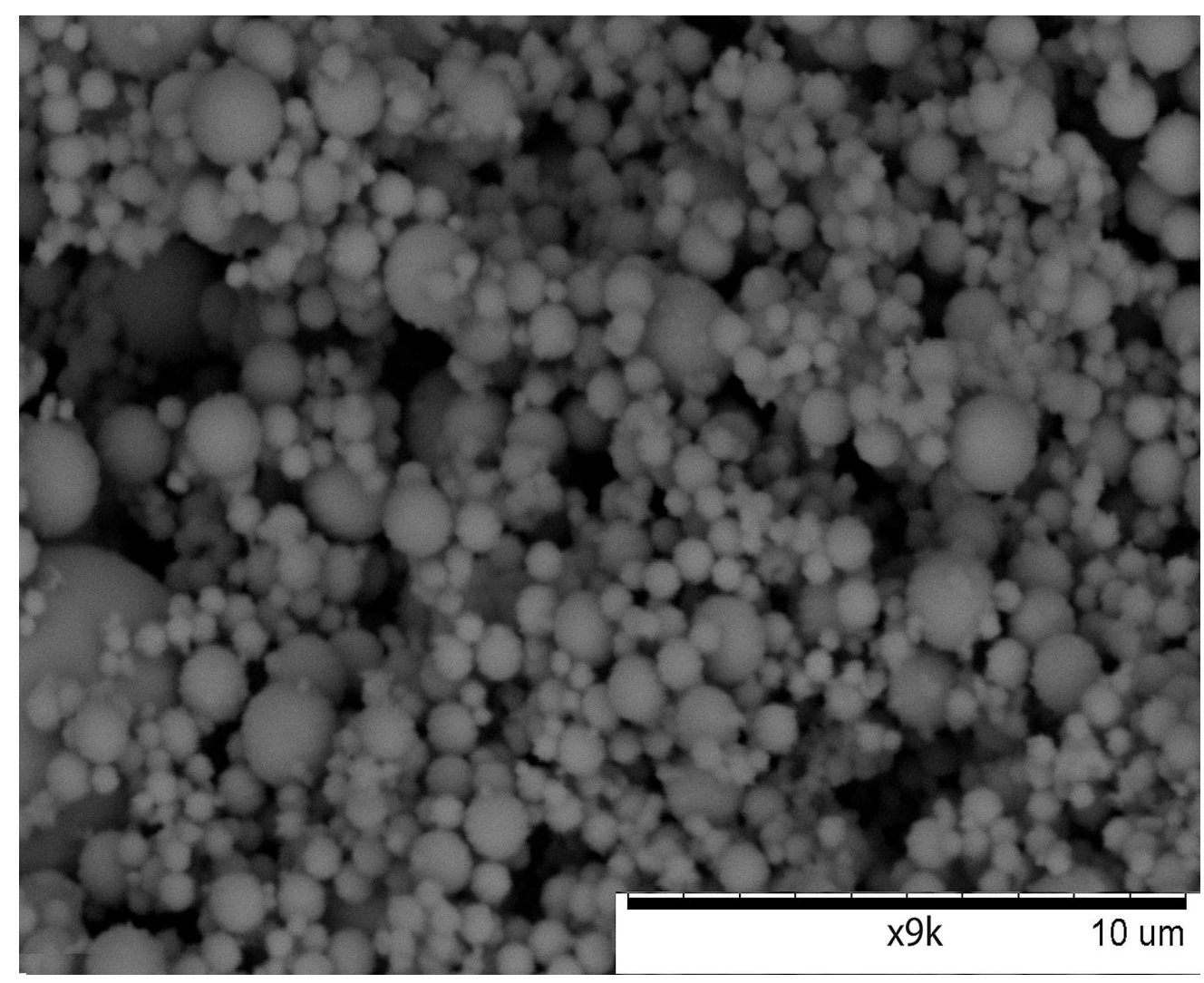

Obtained by forced hydrolysis of NBVI** $190 \times 154 \mathrm{~mm}(300 \times 300$ DPI $)$ 


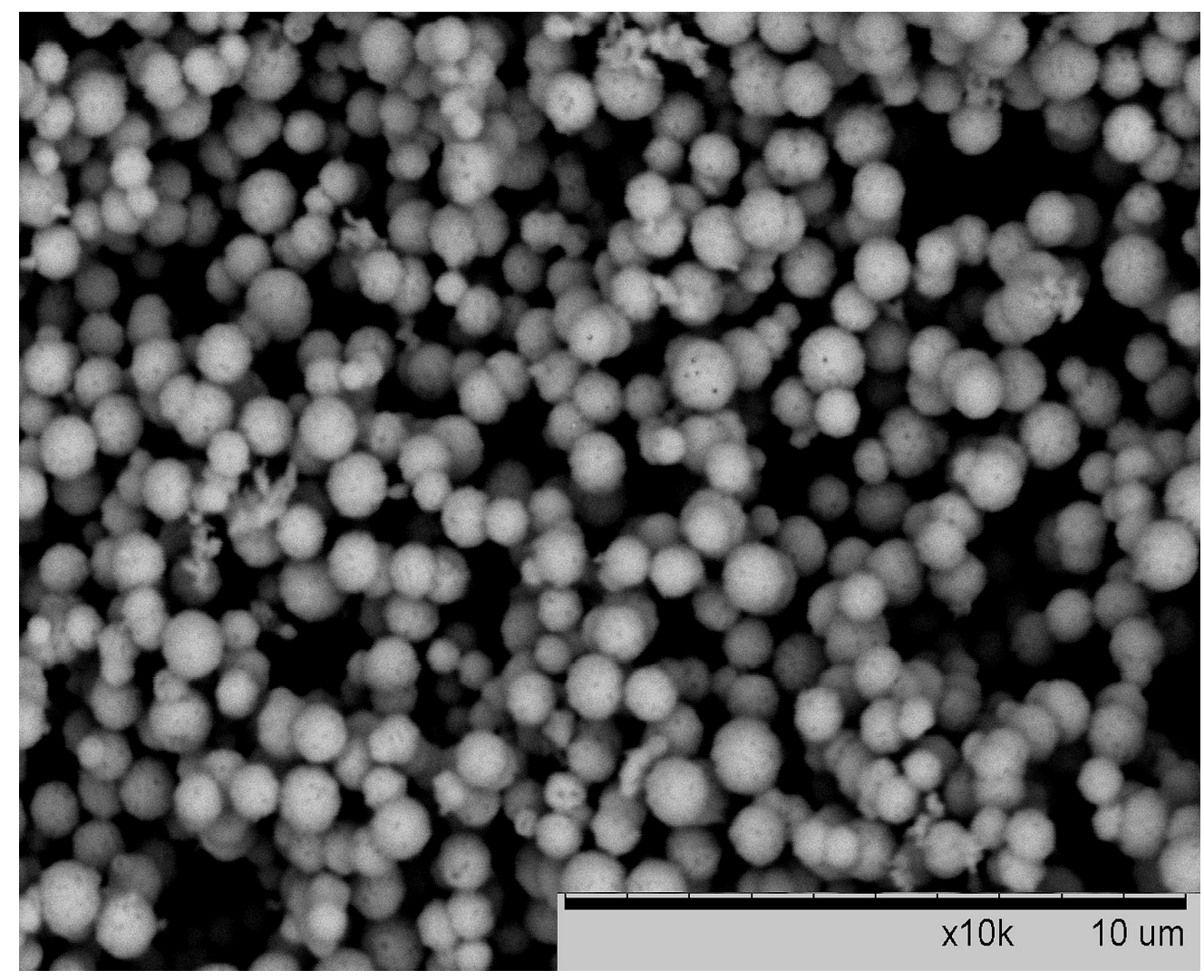

Obtained from NBI

$190 \times 154 \mathrm{~mm}$ (300 x 300 DPI)

36

37

38

39

40

41

42

43

44

45

46

47

48

49

50

51

52

53

54

55

56

57 


\section{Page 35 of 39}

Langmuir

1
2
3
4
5
6
7
8
9
10
11
12
13
14
15
16
17
18
19
20
21
22
23
24
25
26
27
28
29
30
31
32
33
34
35
36
37
38
39
40
41
42
43
44
45
46
47
48
49
50
51
52
53
54
55
56
57
58
60

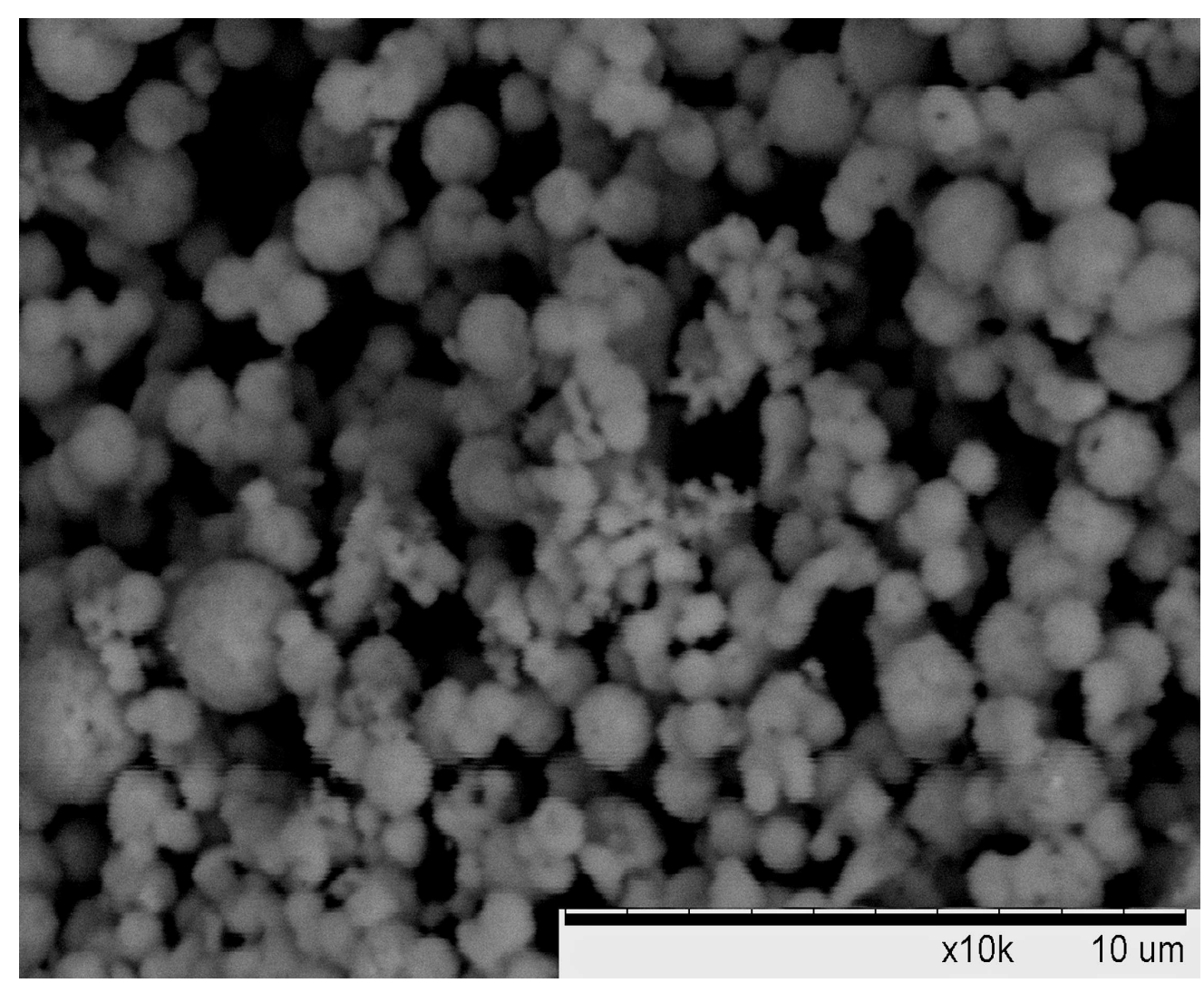

Obtained from NBIII

$190 \times 154 \mathrm{~mm}$ ( $300 \times 300$ DPI) 


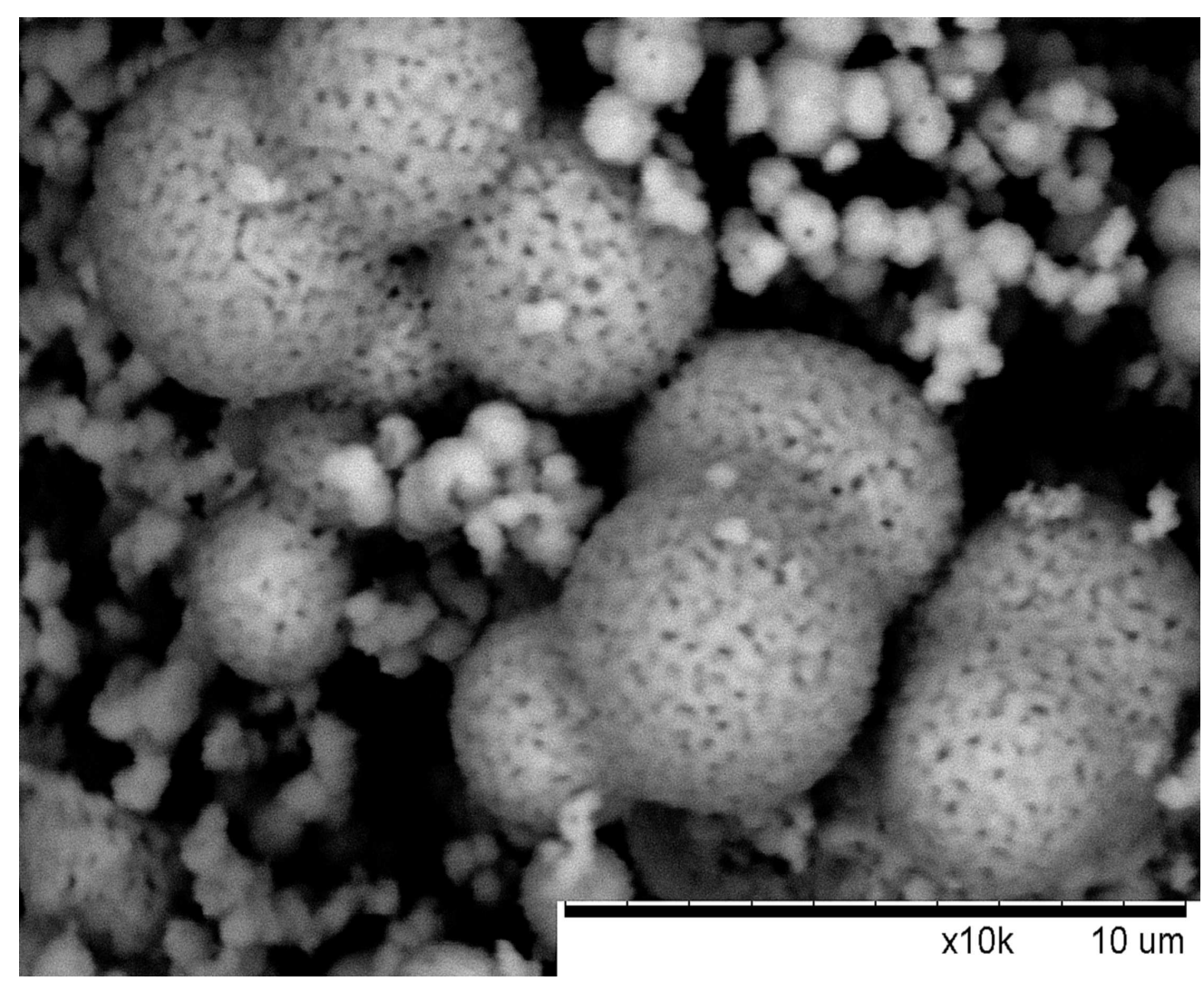

Obtained from NBIV

$190 \times 154 \mathrm{~mm}(300 \times 300$ DPI $)$

36

37

38

39

40

41

42

43

44

45

46

47

48

49

50

51

52

53

54

55

56 


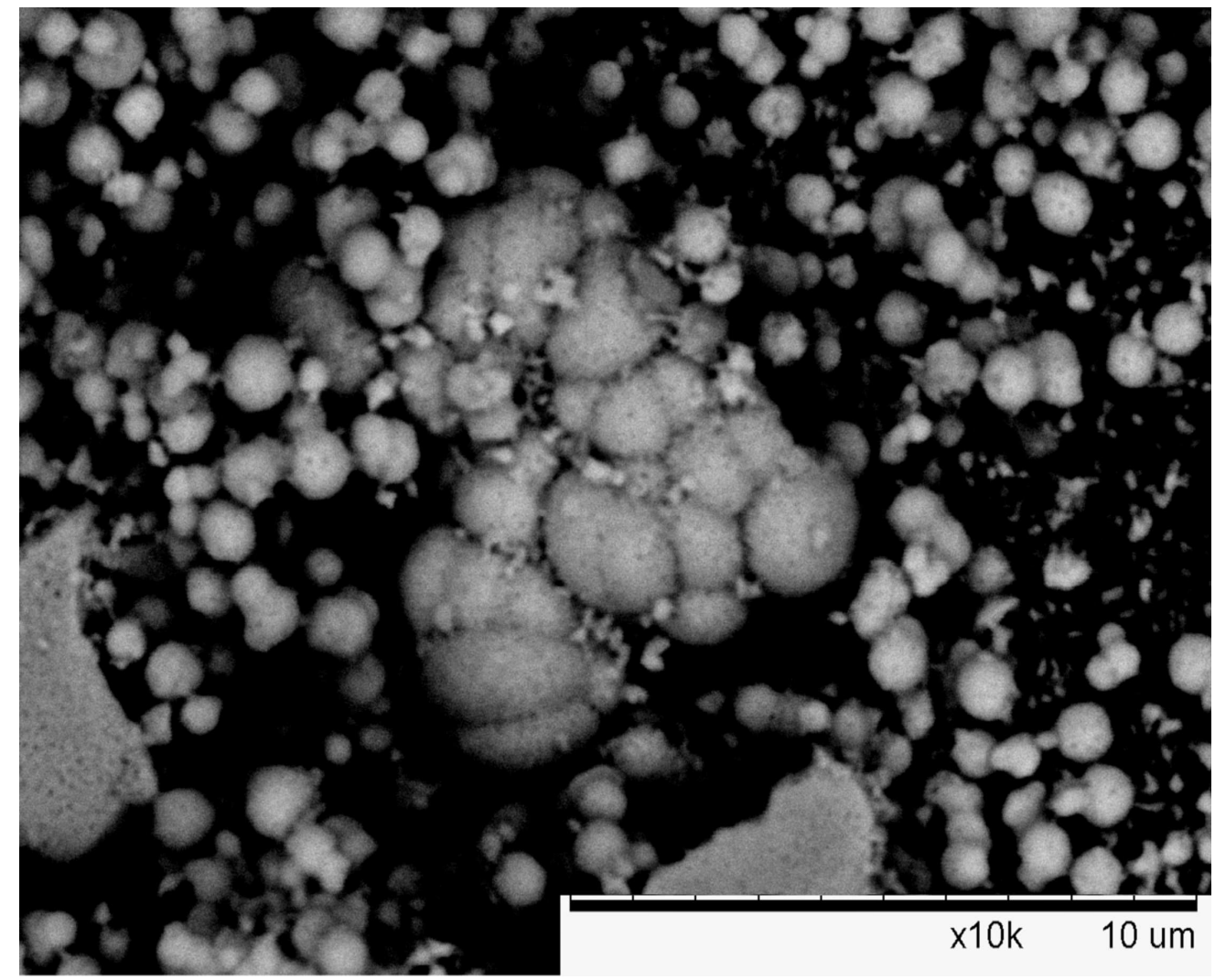

Obtained from NBVI

$190 \times 154 \mathrm{~mm}(300 \times 300 \mathrm{DPI})$ 


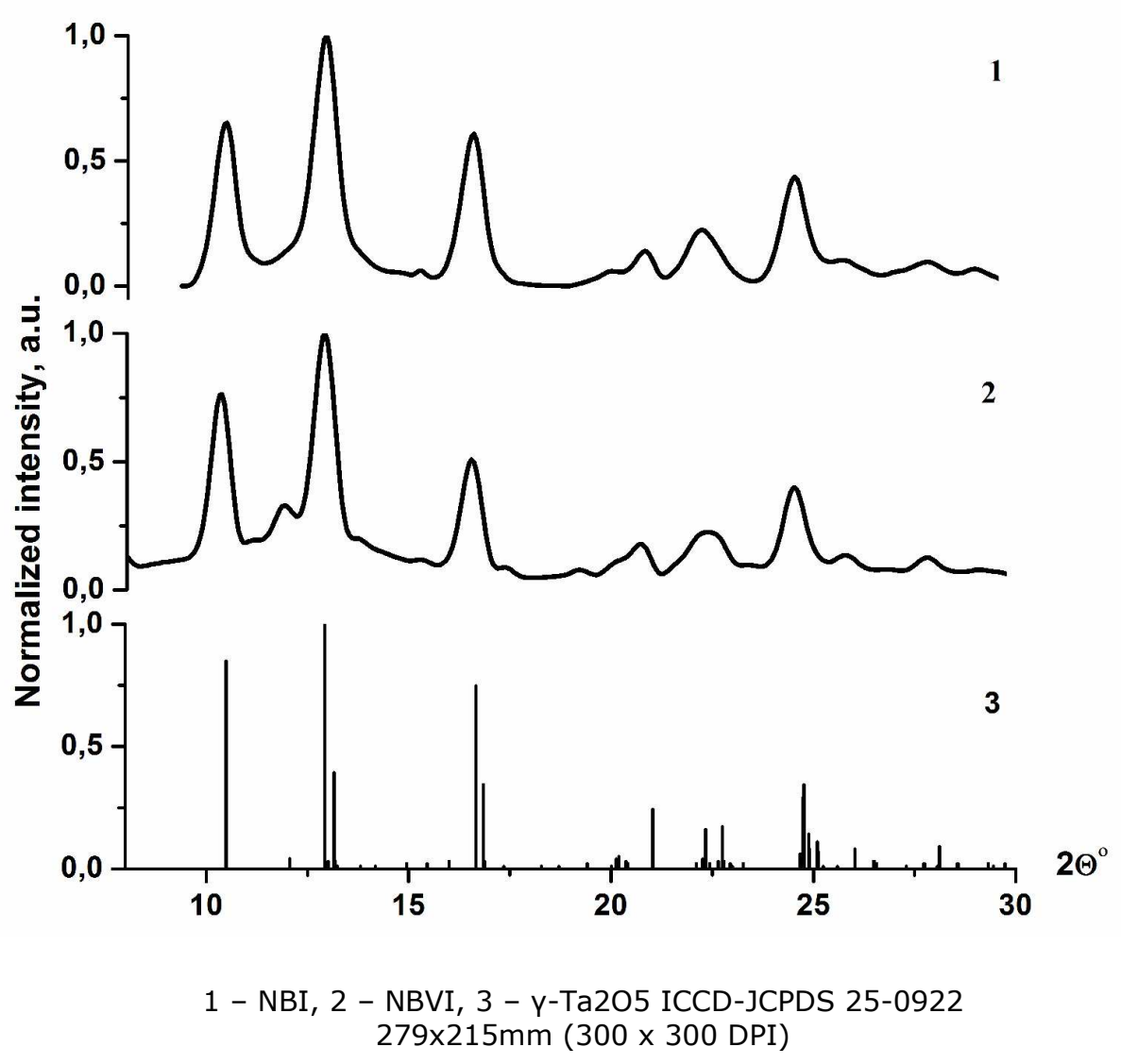




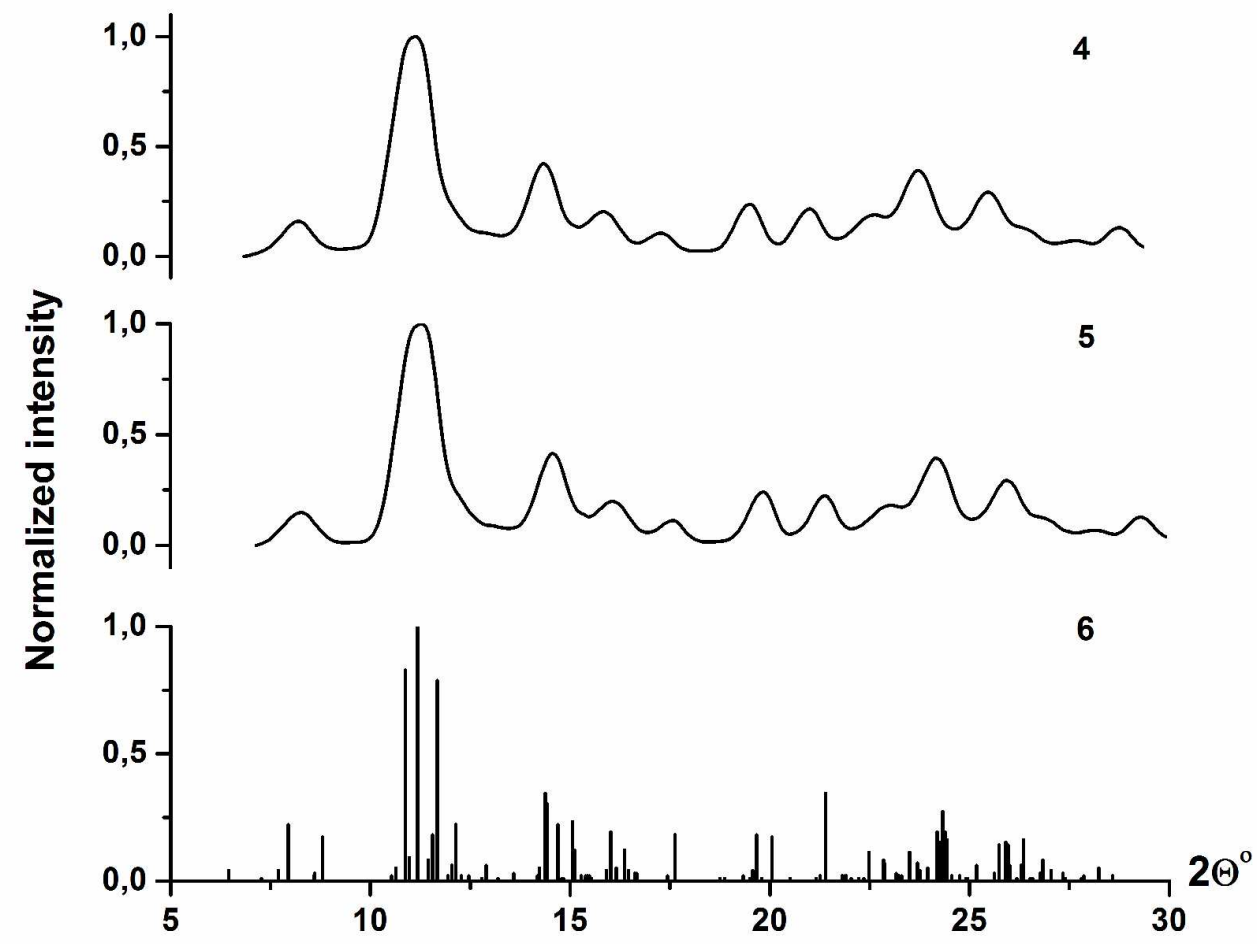

4 - NBIII, 5 - NBIV, 6 - a-Nb2O5 ICCD- JCPDS 37-1468 $279 \times 215 \mathrm{~mm}(300 \times 300 \mathrm{DPI})$ 